\title{
Comparison between Numerical Simulation and On-orbit Experiment of Oscillating Heat Pipes
}

\author{
Takurou Daimaru $^{1}$ and Hiroki Nagai ${ }^{2}$ \\ Tohoku University, Sendai, Miyagi 980-8579, JAPAN \\ Makiko Ando $^{3}$, Kosuke Tanaka $^{4}$, Atsushi Okamoto ${ }^{5}$ and Hiroyuki Sugita ${ }^{6}$ \\ Japan Aerospace Exploration Agency, Tsukuba, Ibaraki 305-8505, JAPAN
}

\begin{abstract}
This study investigated the startup behavior of Oscillating Heat Pipes (OHPs) by comparing numerical simulation and on-orbit experimental data. Previous studies suggested that initial vapor-liquid distribution affects startup behavior. However, they provided no experimental evidence to validate this hypothesis because experimentally reproducing and specifying initial distribution in OHPs is virtually impossible. Thus, a numerical approach is necessary to generate the initial vapor-liquid distribution and to understand the internal thermofluid behavior of OHPs. In this study, a one-dimensional numerical model of an OHP with check valves was first developed. Then, the model was validated by comparing it with data from an on-orbit experiment. Finally, simulation of OHP startup behavior with several types of initial distributions showed that OHP startup difficulty is due to localization of liquids in the cooling section.
\end{abstract}

\section{Nomenclature}

$A_{c r} \quad=$ cross-sectional area of flow path, $\mathrm{m}^{2}$

$A_{w} \quad=$ cross-sectional area of pipe wall, $\mathrm{m}^{2}$

$\mathrm{Ca}=$ capillary number, -

$C_{D} \quad=$ drag coefficient, -

$c_{p} \quad=$ specific heat at constant pressure, $\mathrm{J} / \mathrm{kg} \mathrm{K}$

$c_{v} \quad=$ specific heat at constant volume, $\mathrm{J} / \mathrm{kg} \mathrm{K}$

$D \quad=$ diameter, $\mathrm{m}$

De $\quad=$ dean number, -

$d P \quad=$ pressure difference, $\mathrm{Pa}$

$f \quad=$ friction factor, -

$h \quad=$ heat transfer coefficient, $\mathrm{W} / \mathrm{m}^{2} \mathrm{~K}$

$H_{L G} \quad=$ latent heat of vaporization, $\mathrm{J} / \mathrm{kg}$

$k=$ thermal conductivity, $\mathrm{W} / \mathrm{m} \mathrm{K}$

$L \quad=$ length, $\mathrm{m}$

$m \quad=$ mass, $\mathrm{kg}$

$\dot{m} \quad=$ momentum, $\mathrm{kg} \mathrm{m} / \mathrm{s}$

${ }^{1} \mathrm{PhD}$ Candidate, Department of Aerospace Engineering, 6-6-01 Aramaki-Aza-Aoba, Aoba-ward, Sendai, Miyagi 980-8579, Japan, daimaru.takurou@aero.mech.tohoku.ac.jp

${ }^{2}$ Professor, Institute of Fluid Science, 2-1-1 Katahira, Aoba-ward, Sendai, Miyagi 980-8577, Japan, nagai.hiroki@tohoku.ac.jp

${ }^{3}$ Researcher, Research Unit II, Research and Development Directorate, 2-1-1 Sengen, Tsukuba, Ibaraki 305-8505, Japan, andoh.makiko@jaxa.jp

${ }^{4}$ Researcher, Research Unit II, Research and Development Directorate, 2-1-1 Sengen, Tsukuba, Ibaraki 305-8505, Japan, tanaka.kohsuke@jaxa.jp

5 Associate Senior Researcher, Research Unit II, Research and Development Directorate, 2-1-1 Sengen, Tsukuba Ibaraki, 305-8505, Japan, okamoto.astushi@jaxa.jp

${ }^{6}$ Director, Research Unit II, Research and Development Directorate, 2-1-1 Sengen, Tsukuba, Ibaraki 305-8505, Japan, sugita.hiroyuki@jaxa.jp 


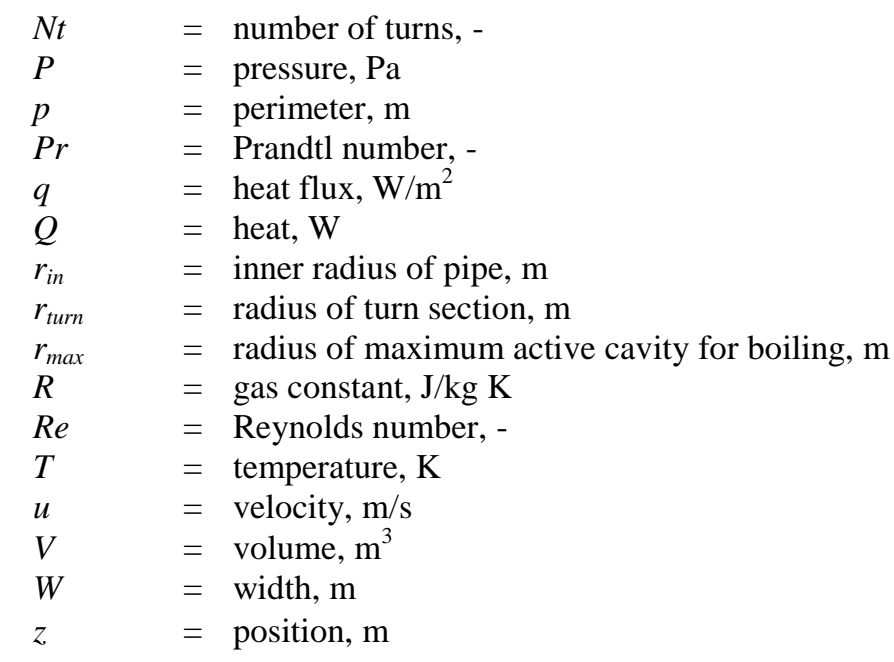

Greek symbols

$\begin{array}{ll}\delta & =\text { thickness, } \mathrm{m} \\ \mu & =\text { viscosity, } \mathrm{Pa} \mathrm{s} \\ \rho & =\text { density, } \mathrm{kg} / \mathrm{m}^{3} \\ \sigma & =\text { surface tension, } \mathrm{N} / \mathrm{m} \\ \xi & =\text { loss coefficient, }-\end{array}$

Subscripts

$\begin{array}{ll}b & =\text { back menisci } \\ c & =\text { cooling section } \\ C V & =\text { check valve } \\ \text { dry } & =\text { dry region in vapor plug } \\ \text { evap } & =\text { evaporative heat transfer } \\ f & =\text { front menisci/working fluid } \\ \text { film } & =\text { liquid film } \\ h & =\text { heating section } \\ i & =\text { index in mesh of liquid slug } \\ j & =\text { index of vapor plug } \\ k & =\text { index in mesh of pipe wall } \\ \text { turn } & =\text { turn section } \\ l & =\text { liquid slug } \\ L & =\text { liquid film in left side } \\ n & =\text { index of liquid slug } \\ n p & =\text { index of heating plate } \\ R & =\text { liquid film in right side } \\ s a t & =\text { saturated condition } \\ v & =\text { vapor plug } \\ w & =\text { pipe wall } \\ \tau & =\text { friction }\end{array}$

\section{Introduction}

N Oscillating Heat Pipe (OHP), also known as a Pulsating Heat Pipe (PHP), is a two-phase heat transfer device $^{1}$ invented in 1990 by $\mathrm{H}$. Akachi in Japan. As shown in Figure 1, an OHP consists of only bended capillary tubes with a heating section at one end and a cooling section at the other. After evacuation, the OHP is charged with a working fluid to almost half of its internal volume. Because of the strong capillary force in tubes with a small diameter, the working fluid is distributed separately as vapor plugs and liquid slugs along the flow path. On application of heat to the heating section, oscillating flow is driven by the pressure difference between each channel. In this manner, the working fluid transports heat from the heating section to the cooling section by a combination of sensible and latent heat transfer. ${ }^{2}$ Because an OHP is usually made from a tube with a very small diameter, it is quite 
thin. Thus, an OHP can transport heat from very narrow spaces with high efficiency. Furthermore, because OHPs do not have a porous structure (wick), they have a very simple flat-plate configuration and are much lighter than conventional heat pipes. As a result of these merits, OHPs have become very attractive as heat transfer devices for next-generation spacecraft.

Several experimental studies have been conducted to understand the basic operational principle of OHPs. Khandekar and Groll $^{3}$ investigated various operations due to heat input using a single-loop OHP. Charoensawan and Khandekar ${ }^{4,5}$ studied the effects of number of turns and length of each section as basic design parameters. Miyazaki ${ }^{6}$ proposed a theoretical oscillatory cycle model,

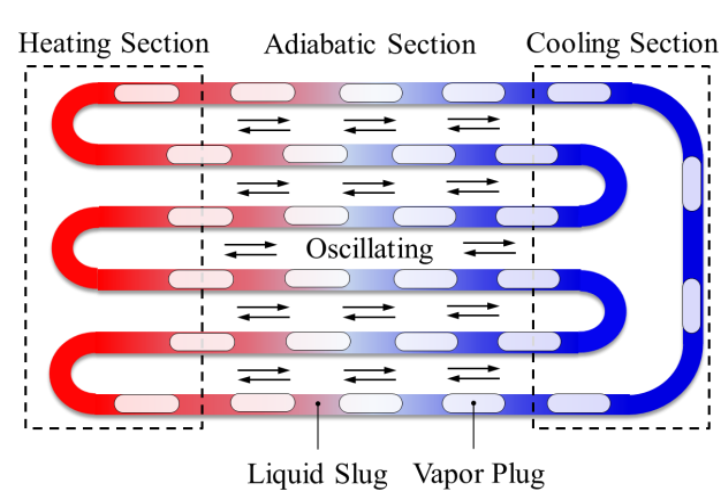

Figure 1. An oscillating heat pipe (OHP). and validated it via pressure measurement in an OHP. Gully et al. ${ }^{8}$ evaluated the vapor thermodynamic state via cryo-experiments. Nikolayev ${ }^{9}$ successfully reproduced Gully's experimental results and analyzed oscillatory instability via numerical simulations. These studies helped to advance understanding of the operational principle of OHPs over the past two decades.

However, under critical operating conditions, the heat transfer performance of the OHP is limited, because liquid and vapor separate completely and travel to the cooling and heating sections, respectively. The separation of liquid and vapor results in low liquid slug oscillation amplitude in the adiabatic section. ${ }^{10}$ This type of oscillating motion is the most serious heat transfer problem affecting OHPs. OHPs with check valves (CVOHP) have been developed to solve this problem. ${ }^{11}$ By installing check valves in the looped channel, the inner flow motion changes from oscillation to circulation. Thus, it is possible to prevent operational limitations due to low-amplitude oscillations. Furthermore, the heat transported as latent heat increases as a result of the phase change of liquid and vapor, which flow through the heating and cooling sections. In addition, improvement of the startup behavior is possible, because the pressure difference is used for one-directional flow more efficiently.

Japan Aerospace Exploration Agency (JAXA) is focused on the potential of CVOHPs and has subsequently developed a Flat-plate Heat Pipe (FHP), ${ }^{12}$ which consists of an CVOHP and a metal plate, as shown Figure 2. In the FHP, the CVOHP is held between metal plates to improve the stability of the system in the spacecraft. Development began with an

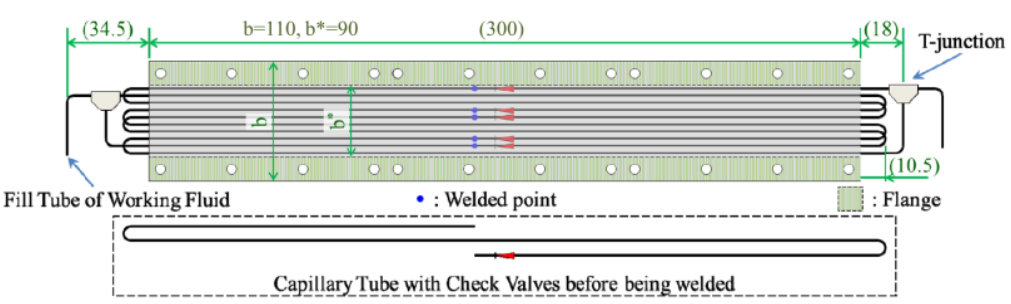

Figure 2. Flat-plate heat pipe (FHP). ${ }^{12}$ investigation of the design parameters, which involved optimization of number of turns, shape of the plate, etc., for heat transfer and dissipation requirement. As a result, an effective thermal conductivity of $6000[\mathrm{~W} / \mathrm{m} / \mathrm{K}]$ was achieved. This value is almost 30 times larger than that obtained with a pure aluminum plate. Finally, the "FHP Onorbit Experiment (FOX)" was conducted to confirm the performance of FHP in a microgravity environment. ${ }^{13}$ In the FOX project, a flight model of FHP was mounted on the Small Demonstrate Satellite-4 (SDS-4) ${ }^{14}$ launched in 2012. In the on-orbit experiment, FHP demonstrated good performance for almost 3 years and 8 months. From this experiment, it was found that the performance of FHP in microgravity does not change from that it in gravitational condition because the thermal conductivity maintained the same values. ${ }^{15}$

However, the FHP did not start up smoothly in several heating timing conditions. ${ }^{15,16}$ In the orbit of SDS-4 (SSO, altitude $677 \mathrm{~km}$ ), the duration of one cycle is about $90 \mathrm{~min}$, eclipse is $30 \mathrm{~min}$, and a day is $60 \mathrm{~min}$. In a standard test case for thermal performance evaluation, the heating timing was after $45 \mathrm{~min}$ at the end of eclipse (middle of a day). For additional test cases for evaluation of the robustness against the thermal environment and startup characteristics, the heating timing differed from the standard condition. As a result of those tests, it was found that FHP tends to not startup or take a long time to start in the eclipse and immediately after. Currently, it is believed that vapor-liquid distribution affects the startup characteristics of FHP because vapor-liquid separation may gradually occur and most of the liquids gather in the cooling section during eclipse. This startup characteristic due to initial distribution is a definite problem for space application. However, evaluation of initial vapor-liquid distribution is quite difficult to 
validate experimentally. Therefore, numerical simulation is necessary to understand the startup phenomena. We have evaluated the effects of initial distribution in the normal OHP, ${ }^{17}$ but not in CVOHP.

Since 2001 several studies have been conducted on numerical modeling of OHP. Shafii et al. ${ }^{18}$ developed a transient one-dimensional model of the slug flow, in which vapor plugs and liquid slugs are separately distributed along the flow path in the OHP. In this model, vapor plugs are treated as an ideal gas (can be both saturated and dry) and liquid slugs are considered as incompressible flow. Energy conservation is solved in both the vapor plug and the liquid slug separately. As a result of energy changes in the vapors, temperature and pressure changes and a pressure difference are generated between vapors. Finally, movements in the liquid slugs are solved based on the local pressure difference between adjacent vapors. The basic structure of the one-dimensional model of the OHP is virtually complete, and several researchers have improved on the model over time. Das et al. ${ }^{19}$ developed a liquid film model in the single-branch OHP. In this OHP, a very thin liquid film exists between the vapor plug and the pipe wall because of strong shearing force in the capillary tube. Heat transfer between the vapor plug and pipe wall is very large as a result of existence of the liquid film compared to the single-flow vapor, because the heat transfer mechanism changes from forced convective heat transfer to conduction through thin liquid film. In addition, they took into account retreating of the liquid film as a result of evaporation. Experimental verification of the model was also conducted. Nikolayev ${ }^{20}$ extended Das's liquid film model to multi-branch OHPs, and numerically modeled most of the basic phenomena in the OHP with slug flow. However, to the best of our knowledge, a practical numerical model does not exist. Conventional numerical models cannot predict thermal performance and reproduce complex transient phenomena because of the lack of a physical model. In this study, a numerical model of CVOHP was developed. In contrast to models previously developed, the current model integrates a pipe wall energy equation, a model of the check valves including pressure loss, detailed boiling phenomena, and pressure loss information from meniscus transformation .

This paper presents the methodology utilized in the proposed CVOHP numerical model. Further, the verification of the model conducted using experimental data from the on-orbit experiment is outlined. Finally, the startup problem experienced in the on-orbit experiment as a result of the effects of vapor-liquid initial distribution is discussed.

\section{Numerical Modeling}

A schematic diagram of the numerical model is shown in Figure 3. It is a onedimensional model along the flow path and has parts of the pipe wall, plates in the heating and cooling section, check valves, and working fluid. As shown in Figure 4, the working fluid domain consists of liquid slugs, vapor plugs, and liquid films. The pipe wall and each liquid slug have meshes for temperature calculation. The mesh of the pipe wall is fixed spatially, whereas the meshes of the liquids can move in the working fluid domain. The following assumptions were made during the development of the model:

a) The inner flow regime is slug flow, which is uniform along the radial direction.

b) The liquid phase is incompressible flow.

c) Vapor plugs are treated as an ideal gases.

d) Temperature and pressure are uniform within each vapor plug.

e) Liquid films do not flow because of strong shear forces within the pipe inner surface. Friction between vapor plugs and films is not considered.

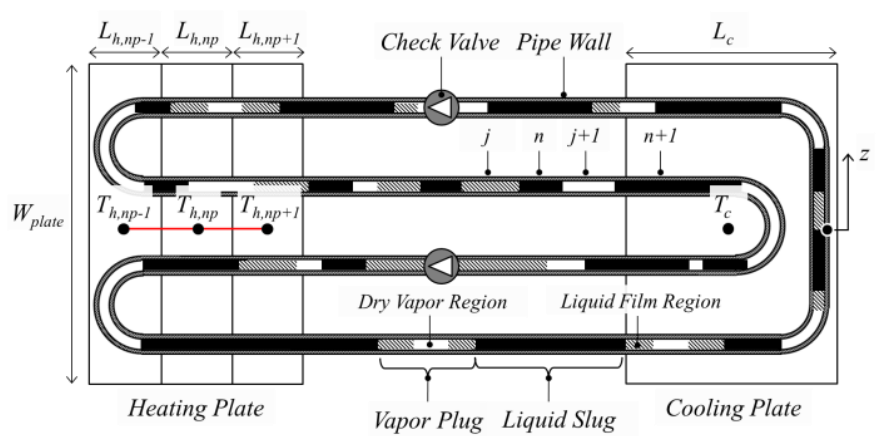

Figure 3. Schematic diagram of proposed numerical model

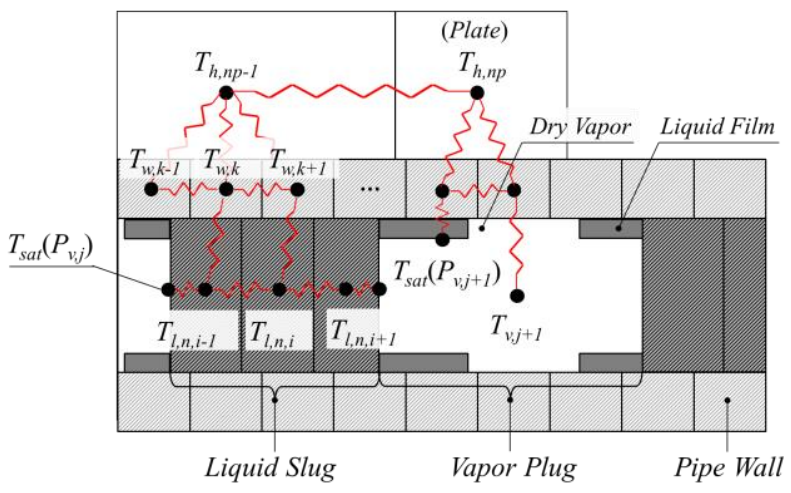

Figure 4. Thermal network 
f) Mass and volume changes in the liquid slugs as a result of the generation and absorption of liquid films and via phase change in an interface with vapors are not taken into account.

g) Correlations in steady-state developed flow are used for calculation of heat transfer coefficients in transient and turbulent flow and friction factor for liquid slugs in a laminar and turbulent flow.

h) When boiling occurs in the liquid slug, many small bubbles are generated. These bubbles merge into a larger bubble instantly, which is the same size as the inner diameter of the pipe.

i) The front and rear meniscus of liquid slugs are treated as flat cross sections in terms of heat transfer, but pressure loss due to transformation of a meniscus is taken into account.

j) Heat transfer of the heating and cooling plates is taken into account, but it is not considered in the adiabatic section.

A flowchart of the calculation procedure is shown in Figure 5. Calculation is implemented in each sub-section. The equations used for these calculations are presented and explained in appendix.

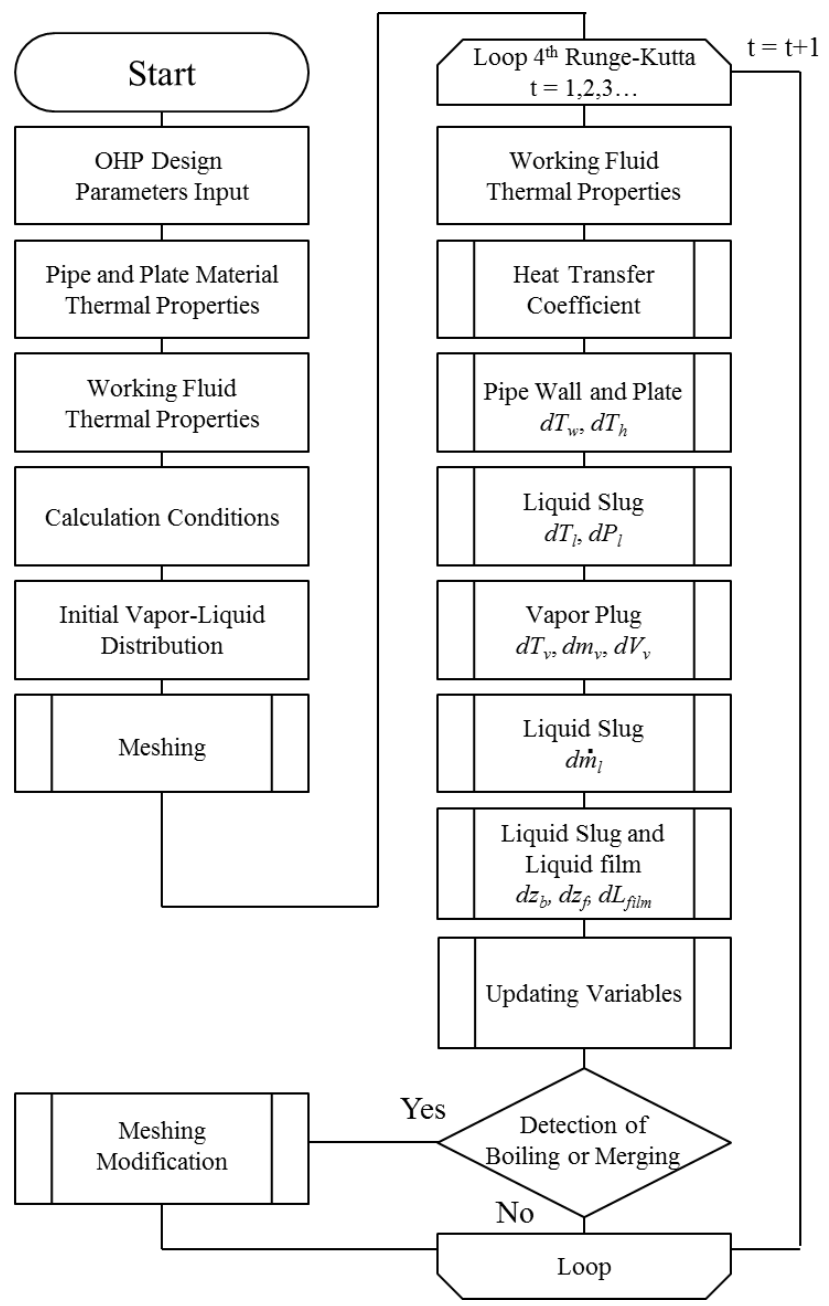

Figure 5. Flowchart of the calculations performed in the proposed model

\section{Comparison with On-orbit Experiment}

To validate the numerical model, we compared the results obtained to those from the On-orbit Experiment (FOX). The configuration of the FOX flight model is shown in Figure 6 and Table 1. The FHP is bent into a Ushape to fit into a small space in SDS-4. As shown in Figure 7, the FHP was mounted on the side panel, which is used as the cooling section. The entire FHP was insulated via multi-layer insulation. The temperature of the panel increases in the day and decreases in the eclipse. As mentioned in the introduction, the heating timing is after 45 min following the end of the eclipse in the experiment. This timing allows the vapor and liquid to distribute almost equally in each section because liquids may move toward the heating section as a result of increased panel temperature. For the calculation condition, we employed the timing, where the temperature of the cooling section is highest and the ideal vapor-liquid distribution. The FHP was tested with three different heat inputs. The heater assignment is shown in Table 2. The area of the heating section and temperature in the cooling section changed in accordance with the amount of heat input. The calculation conditions are shown in Table 3 . In this calculation, the temperature will rise immediately after boiling because the mass of the vapor is too small. Thus, the size of the time step was sufficiently small to facilitate capture of the motion of the vapor plug. The contact heat transfer coefficient was set sufficiently high because the CVOHP and the metal plate are welded in the FHP, and they may have a strong heat transfer connection. The liquid film thickness for evaporation was estimated using empirical correlation, where the mean flow velocity of liquid slugs was assumed to be approximately $0.4[\mathrm{~m} / \mathrm{s}]$ at $20\left[{ }^{\circ} \mathrm{C}\right]$. The film thickness for condensation was set to twice that of the evaporation. These values will be compared with the numerical results later. 


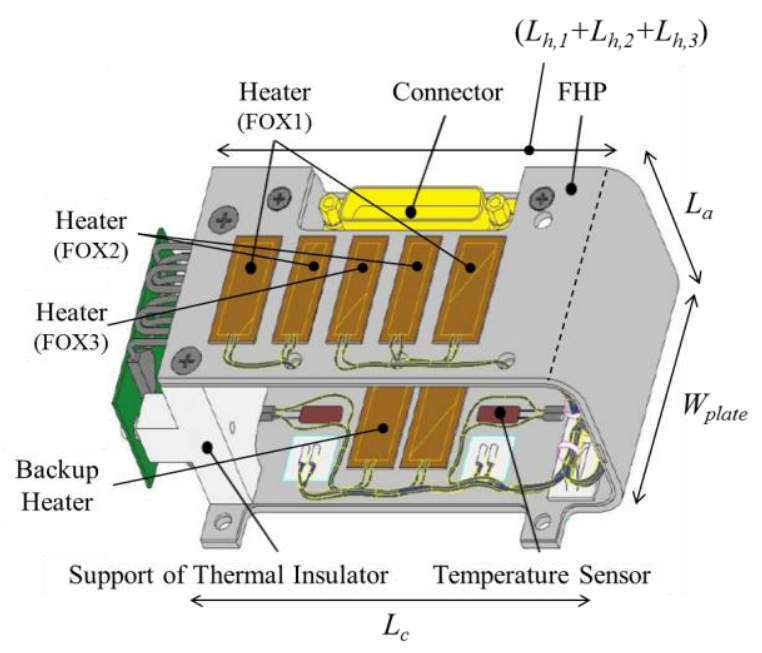

Figure 6. Configuration of the FOX flight model ${ }^{13,15,16}$

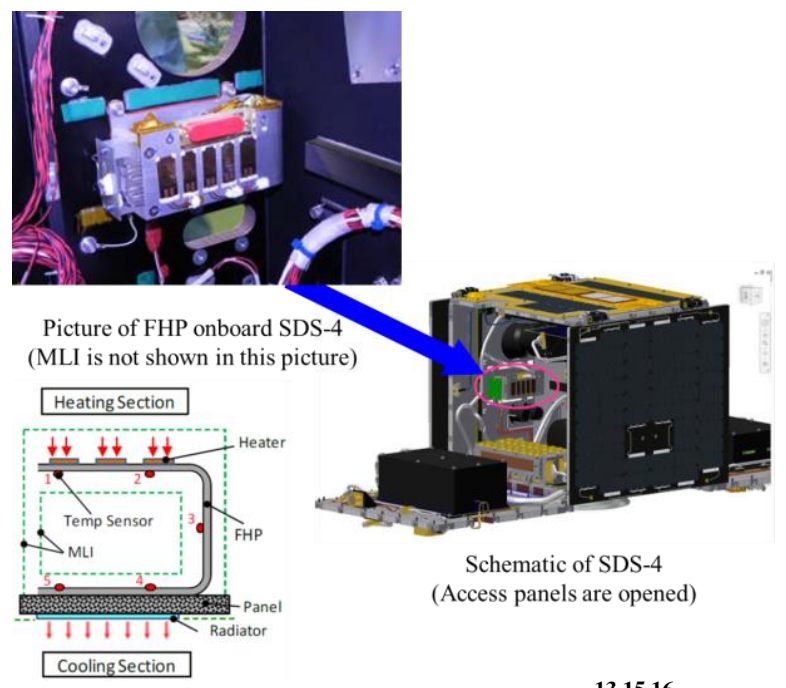

Figure 7. FOX FM in the SDS-4 ${ }^{13,15,16}$

Table 1. Configuration of the FOX flight model

\begin{tabular}{|c|c|c|c|}
\hline Pipe wall material & & Stainless steel & {$[-]$} \\
\hline Working fluid & & HFC-134a & {$[-]$} \\
\hline Charging ratio & & $45 \pm 2.5$ & [wt \%] \\
\hline Length of upper section & $\left(L_{h, 1}+L_{h, 2}+L_{h, 3}\right)$ & 108.6 & {$[\mathrm{~mm}]$} \\
\hline Length of bottom section (cooling section) & $L_{c}$ & 108.6 & {$[\mathrm{~mm}]$} \\
\hline Length of middle (including bent section) & $L_{a}$ & 54 & {$[\mathrm{~mm}]$} \\
\hline Tune diameter (Inner/Outer) & $D_{\text {in }} / D_{\text {out }}$ & $0.8 / 1.6$ & {$[\mathrm{~mm}]$} \\
\hline Radius of turns & $r_{\text {turn }}$ & 3 & {$[\mathrm{~mm}]$} \\
\hline Number of turns & $N t$ & 10 & {$[-]$} \\
\hline Number of check valves & & 5 & {$[-]$} \\
\hline Diameter of ceramic ball in check valves & & 0.5 & {$[\mathrm{~mm}]$} \\
\hline Diameter of ball seat in check valves & & 0.3 & {$[\mathrm{~mm}]$} \\
\hline Total length & $L_{\text {total }}$ & 271.2 & {$[\mathrm{~mm}]$} \\
\hline Total pipe length & & 2994 & {$[\mathrm{~mm}]$} \\
\hline Width (including plate) & $W_{\text {plate }}$ & 60 & {$[\mathrm{~mm}]$} \\
\hline Plate thickness & $\delta_{\text {plate }}$ & 3 & {$[\mathrm{~mm}]$} \\
\hline Weight & & 0.26 & {$[\mathrm{~kg}]$} \\
\hline Heater power & $Q_{\text {in }}$ & $2.6,6.2,11.1$ & {$[\mathrm{~W}]$} \\
\hline Heat flux (corresponding to $Q_{i n}$ ) & $q_{e x}$ & $8666,7948,8044$ & {$\left[\mathrm{~W} / \mathrm{m}^{2}\right]$} \\
\hline
\end{tabular}

Table 2. Heater assignment

\begin{tabular}{ll}
\hline Heater power $[\mathrm{W}]$ & Heater Name \\
\hline \hline 2.6 & FOX3 \\
\hline 6.2 & FOX1 \\
\hline 11.1 & FOX1, FOX2 \\
\hline 2.6 & Backup heater \\
\hline
\end{tabular}


Table 3. Calculation conditions

\begin{tabular}{llll}
\hline \hline Numerical method & & \multicolumn{2}{l}{ Fourth order Runge-Kutta method } \\
\hline Time step & $d t$ & 0.0001 & {$[\mathrm{~s}]$} \\
\hline Number of time steps & $N_{\text {time }}$ & 1000000 & {$[-]$} \\
\hline Computational time & $d t \times N_{\text {time }}$ & 100 & {$[\mathrm{~s}]$} \\
\hline Mesh size for pipe wall & $d z$ & 1 & {$[\mathrm{~mm}]$} \\
\hline $\begin{array}{l}\text { Temperature of cooling plate } \\
\text { (corresponding to } Q_{\text {in }} \text { ) }\end{array}$ & $T_{c}$ & $9.2,15.6,23.9$ & {$\left[{ }^{\circ} \mathrm{C}\right]$} \\
\hline Initial temperature & & & \\
\hline Contact heat transfer coefficient & $T_{\text {int }}$ & $9.2,15.6,23.9$ & {$\left[{ }^{\circ} \mathrm{C}\right]$} \\
\hline Liquid film thickness for evaporation & $h_{\text {contact }}$ & 5000 & {$\left[\mathrm{~W} / \mathrm{m}^{2} / \mathrm{K}\right]$} \\
\hline Liquid film thickness for condensation & $\delta_{\text {film,evap }}$ & 25 & {$[\mu \mathrm{m}]$} \\
\hline Radius of maximum active cavity for boiling & $r_{\text {max }}$ & 50 & {$[\mu \mathrm{m}]$} \\
\hline Initial number of liquid slugs & $N_{l, \text { int }}$ & 1 & {$[\mu \mathrm{m}]$} \\
\hline Initial length of liquid slugs & $L_{l, \text { int }}$ & 40 & {$[-]$} \\
\hline
\end{tabular}

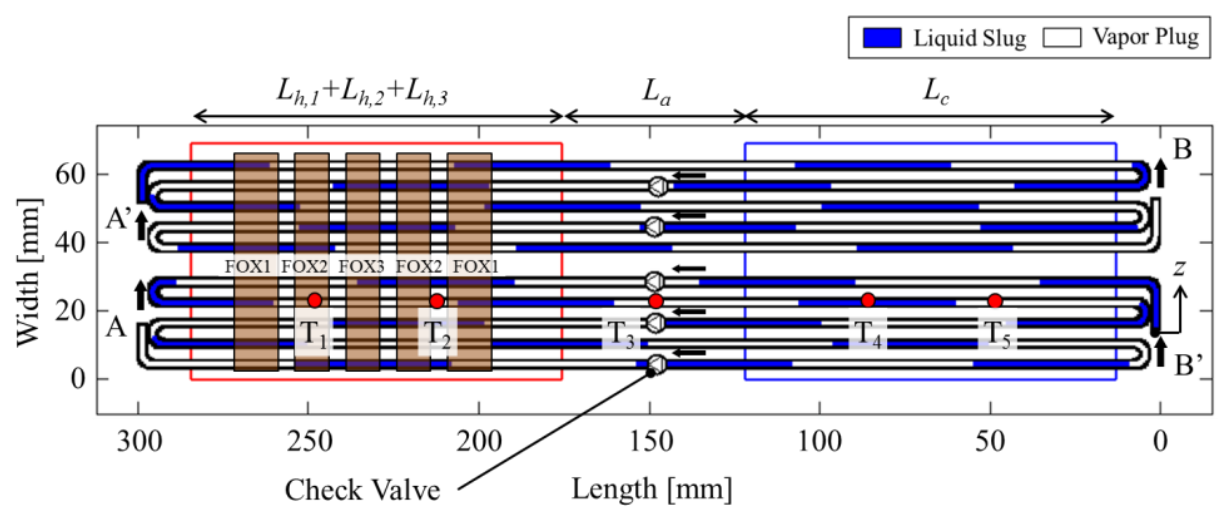

Figure 8. Computational domain and initial vapor-liquid dstribution

Figure 8 shows the computational domain and initial vapor-liquid distribution. The FHP is divided into two parts in order to be seen clearly in the figure. Pipes connect in each of the positions A-A' and B-B'. Check valves exist at the center of the adiabatic section. The check valves are pointed toward the heating section. Liquid slugs are equally distributed in the flow path in the initial distribution. A liquid film surrounds the vapor plugs, which exist between liquid slugs. These relations between liquid slug, vapor plug, and liquid film mean that the entire region of vapor plugs is saturated in the initial condition.

Figure 9 shows the temperature histories of each point in the pipe wall of Figure 8. In all cases of heat input, the temperatures in the heating section increased and almost converged within the calculation time. From these results, it was found that the FHP successfully started up in all conditions. The temperatures in the heating section, $T_{1}$ and $T_{2}$, changed virtually simultaneously. The same applies to the temperatures in the cooling section, $T_{4}$ and $T_{5}$. Thus, the largest temperature gradient within the FHP exists in the adiabatic section. This feature is congruent with the experimental results. Moreover, the time averaged temperature from 90 [s] to 100 [s] is shown in Figure 10. Only the representative temperatures in the heating and cooling section are plotted. The experimental results were obtained using the data associated with the highest temperature in the cooling section. Compared with experimental data, the numerical results show quantitative agreement. The error between the experiment and calculation is 1.0 $\left[{ }^{\circ} \mathrm{C}\right]$ at $2.6[\mathrm{~W}], 0.9\left[{ }^{\circ} \mathrm{C}\right]$ at $6.2[\mathrm{~W}]$, and $1.7\left[{ }^{\circ} \mathrm{C}\right]$ at $11.1[\mathrm{~W}]$, in terms of the temperature of the heating section. These results show that the developed numerical model is valid.

Further, the magnitude of momentum increased with increased heat input. This is because a larger pressure difference could be generated as the driving force with a higher heat input. Similarly, the mean velocity of the liquid slugs increased with heat input, as shown Figure 12. Figure 13 shows the basic frequencies for liquid slug fluctuation calculated using Fast Fourier Transform. As with the velocity, the basic frequency increased with increased heat input. Therefore, the fluid motion is oscillational circulation with small velocity and long period in small heat input. This changes to a flow with large velocity and short period with higher heat input. These changes may be the result of the effect of the boiling phenomenon. 


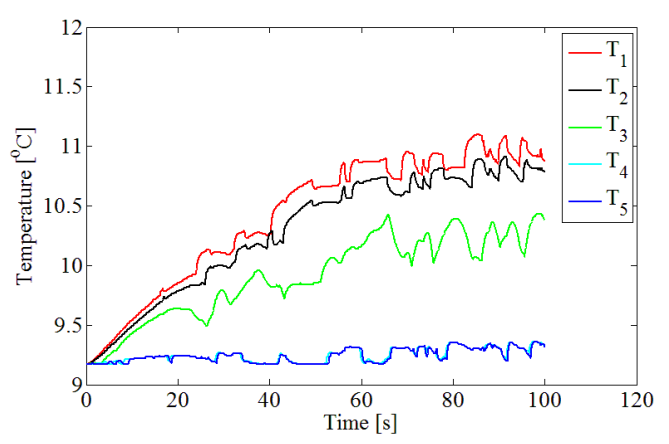

(a) Heat input $Q_{\text {in }}=\mathbf{2 . 6}[\mathrm{W}]$

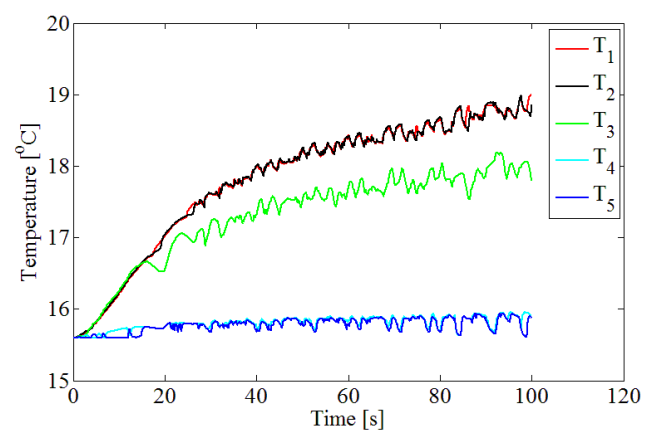

(b) Heat input $Q_{\text {in }}=6.2[\mathrm{~W}]$

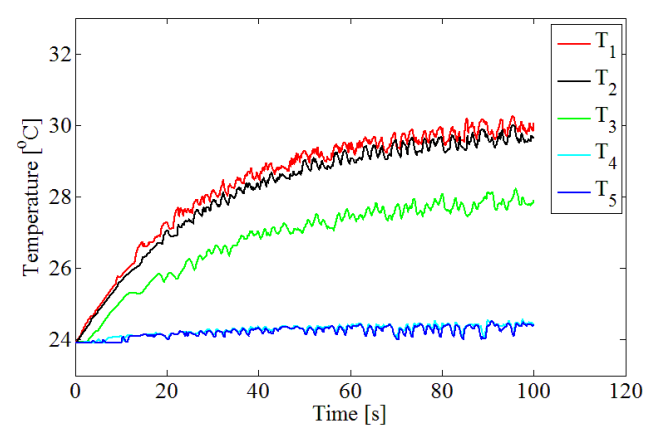

(c) Heat input $Q_{\text {in }}=11.1$ [W]

Figure 9. Temperature histories of the pipe wall

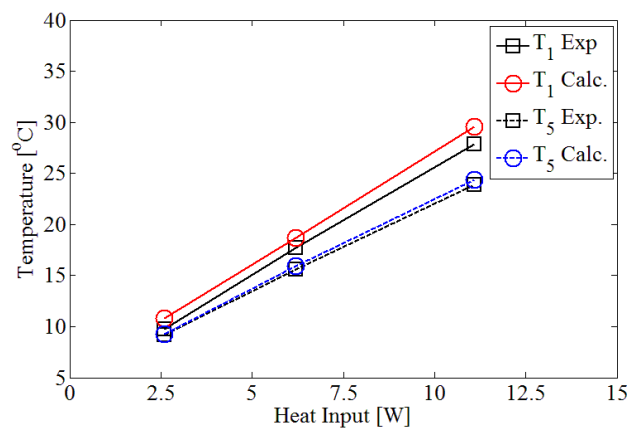

Figure 10. Average temperature

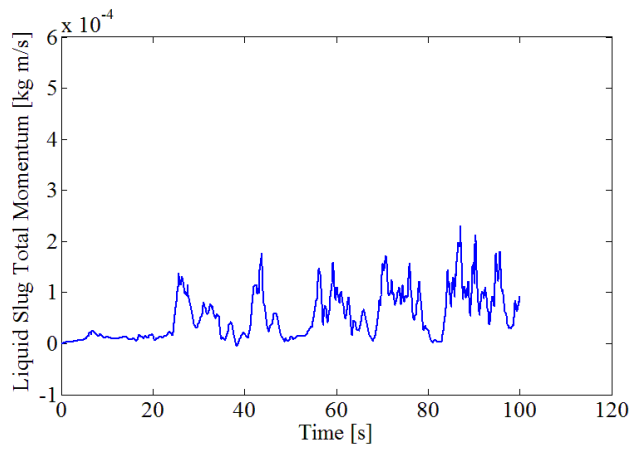

(a) Heat input $Q_{i n}=2.6[\mathrm{~W}]$

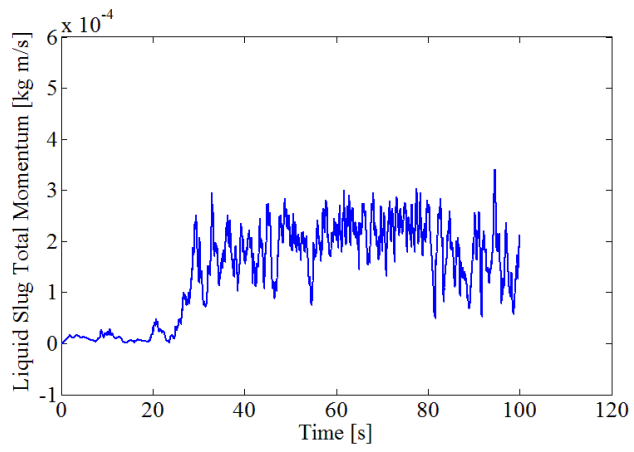

(b) Heat input $Q_{i n}=6.2[\mathrm{~W}]$

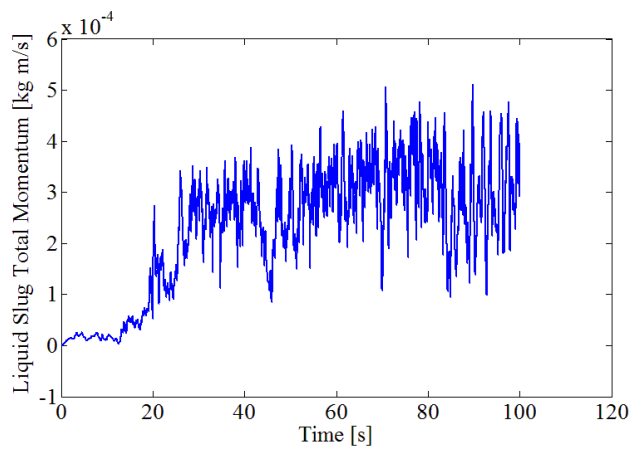

(c) Heat input $Q_{i n}=11.1[\mathrm{~W}]$

Figure 11. Total momentum of the liquid slugs

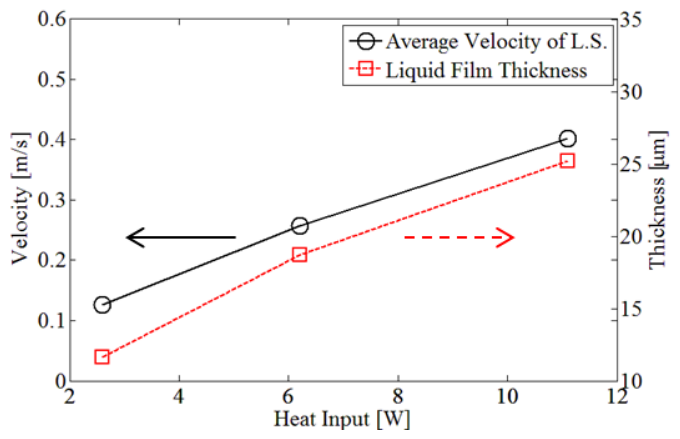

Figure 12. Flow velocity and liquid film thickness 


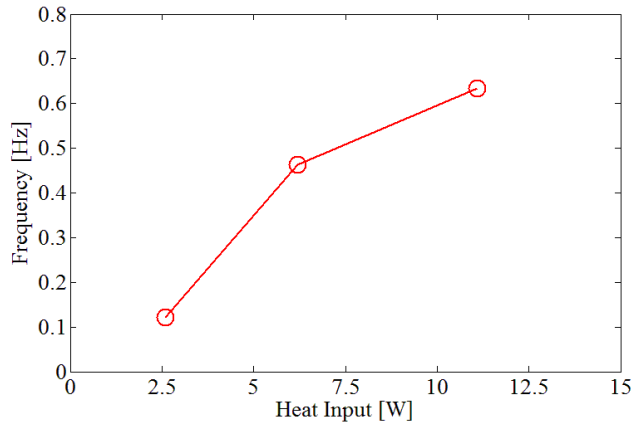

Figure 13. Governing frequency

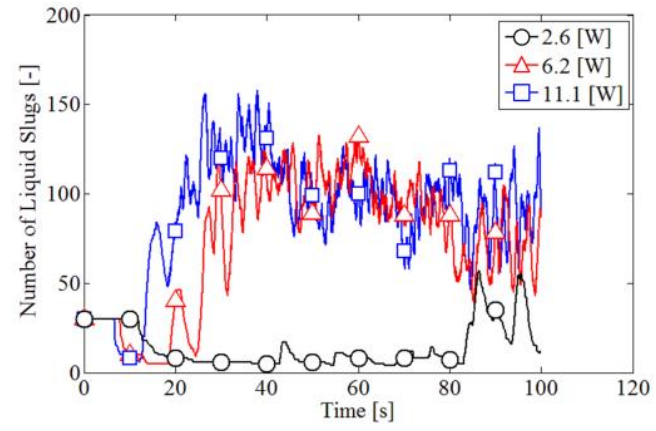

Figure 14. Number of liquid slugs

Figure 14 shows the histories of a number of liquid slugs. In the cases of 6.2 and 11.1 [W], the number of liquid slugs increased as a result of frequent boiling and remained at approximately 100. On the other hand, the number of liquid slugs decreased and remained at a small number, because heat input is not sufficient in the case of 2.6 [W]. Because heat transfer is fast and a bubble can grow immediately after boiling, this may cause fast and short-period flow at higher heat input. Finally, the liquid film thickness is also shown in Figure 12. The assumed value of the liquid film thickness for evaporation was $25[\mu \mathrm{m}]$. Compared with the calculated results, the assumed value almost corresponds to the results in the case of 11.1 [W]. Thus, this value was within the available range of thickness. However, this assumption might make the performance worse and increase error, because it is thicker for lower heat input.

\section{Effects of initial distribution on startup behavior}

Finally, let us look at the effect of the initial vapor-liquid distribution for the FHP startup process. Figure 15 shows a sample result obtained during the on-orbit experiment, and schematic of the expected vapor-liquid distribution. In this case, the heat input was 2.6 [W] and heating timing was $10 \mathrm{~min}$ after the end of eclipse. As mentioned in above, it has been reported that the FHP had difficulty starting up during and immediately after the eclipse in the on-orbit experiment. Thus, it could be that vapor-liquid separation gradually occurs during the eclipse and liquids localize in the cooling section at the end of the eclipse. In fact, the FHP has been able to startup in the test with preconditioning by using a backup heater in the cooling section even during the eclipse. This implies that the FHP can start when liquid slugs exist in the heating section. This is because boiling or expansion of small vapors that survive during eclipse may occur in the cooling section and liquid slugs can come into the heating section using the backup heater.

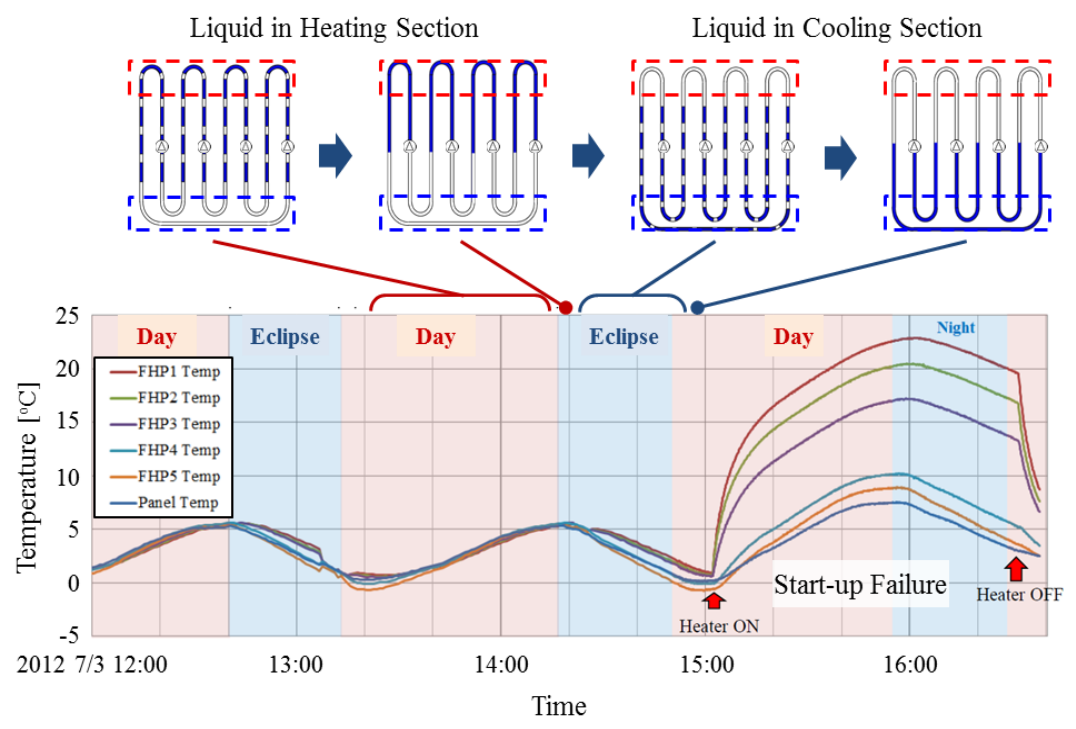

Figure 15. Schematic of expected vapor-liquid distribution during on-orbit experiment ${ }^{15}$ 


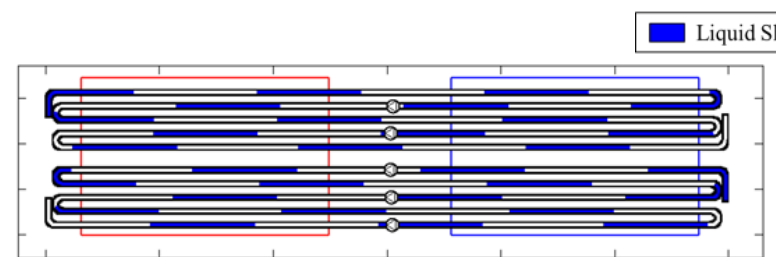

(a) Equal distribution

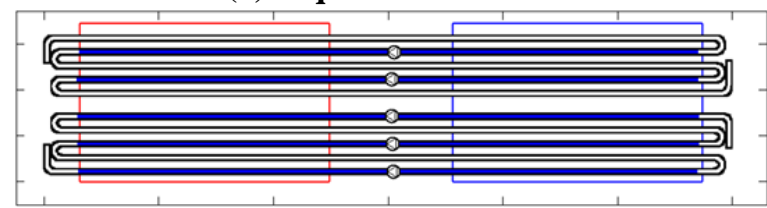

(c) Localization in middle section

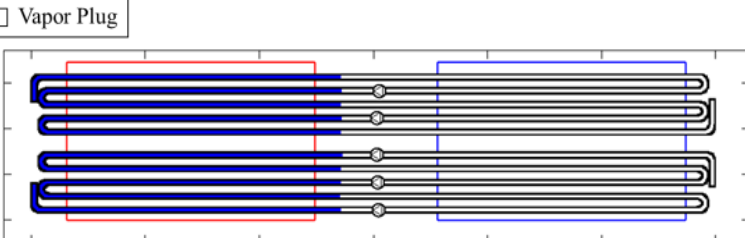

(b) Localization in heating section

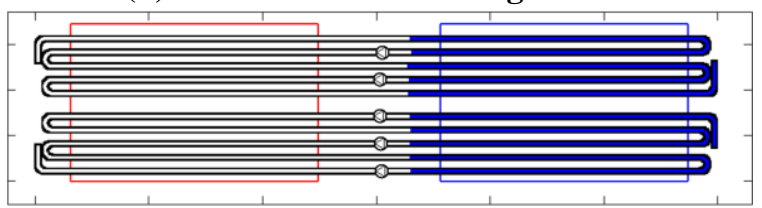

(d) Localization in cooling section

Figure 16. Patterns of initial vapor-liquid distribution

Therefore, in the numerical simulation, four different types of initial vapor-liquid distributions, shown in Figure 16 , were employed to verify the expected vapor-liquid distributions. Figure 16(a) is equal distribution, in which vapor and liquid are distributed equally in the flow path. This case has already been tested in section III. Figure 16(b) is localization in the heating section. This case assumes a situation in which liquids gather in the heating section during the day. Figure 16(c) is localization in the cooling section, which imitates the condition during the eclipse. Figure 16(d) is localization in the middle section. This distribution may occur in the transition between the eclipse and day. Liquid slugs exist straddling the position of the check valves. The filling ratio of the working fluid was 45 [\%], same as in the previous case. In the cases of localization, the length of liquid slugs was set for the meniscus to locate in the same position along the direction of the length of the FHP. Heat inputs were 2.6 and 11.1 [W], to confirm the difference between lower and higher heat inputs. The remaining parameters used in the calculation remained the same as in the previous calculations.

Let us first look at the 2.6 [W] heat input case. In Figure 17, FHP startup was successful, and it operated as a heat transport device in the simulated cases, except for the localization in the cooling section. These results suggest that the FHP can begin operation if liquid slugs exist in the heating section. In addition, among the cases in which FHP started, no clear difference appears for thermal performance. These results agree with the experimental data in the on-orbit experiment, because the thermal performance of FHP maintained the same values for almost 3 years and 8 months. Even if the heating timing is the same in all test cases, the initial distribution should have some level of dispersion. From this viewpoint, one may say that the thermal performance of the FHP is independent of initial vapor-liquid distribution, once it can start. Now, focusing on the case of localization in the cooling section, temperatures in the heating section increased linearly up to almost $14\left[{ }^{\circ} \mathrm{C}\right]$. It did not converge because calculation time was shorter than the experiment. Simultaneously, temperatures in the cooling section did not change. Lack of temperature change means that the FHP could not start operating. However, a small amplitude oscillation can be seen in the momentum history in Figure 18(c). This oscillation developed and caused small peaks at around 90 [s] and100 [s]. Figure 19 shows the liquid slug position at 90 [s] in this case. Here, the liquid slugs moved slightly from their original positions. The movement of the liquid slugs from the original position implies a possibility to change from small oscillation to an entire circulation movement. This phenomenon can be related to the case where time is needed to startup in the on-orbit experiment.

Next, let us look at the 11.1 [W] heat case, shown in Figures 20 and 21. The FHP could operate in the case of localization in the heating and middle sections as same as lower heat input cases. In the localization in cooling section, the FHP did not start either in higher heat input. However, a small momentum oscillation occurred in this case too. From these results, it can be said that the general initial vapor-liquid distribution trend is the same in both lower and higher heat inputs.

Finally, let us look at the effects of boiling on startup. Figures 22 and 23 show the histories of a number of liquid slugs for each heat input. In the cases at 2.6 [W], the number decreased gradually for the case of equal distribution. On the other hand, the number increased in the case of localization in the heating section at around 20 and $30 \mathrm{~s}$. Then, the case of localization in the middle section started increasing from $40 \mathrm{~s}$. Similarly, the case of equal distribution had a small peak at around $45 \mathrm{~s}$. These results show that boiling occurred easily where liquids exist in the heating section. In the case of localization in the heating section, liquids did not move until boiling occurred, because it could not get sufficient driving force owing to the lower pressure of the vapor plugs existing in the cooling section. Thus, boiling is necessary to start in this case. 


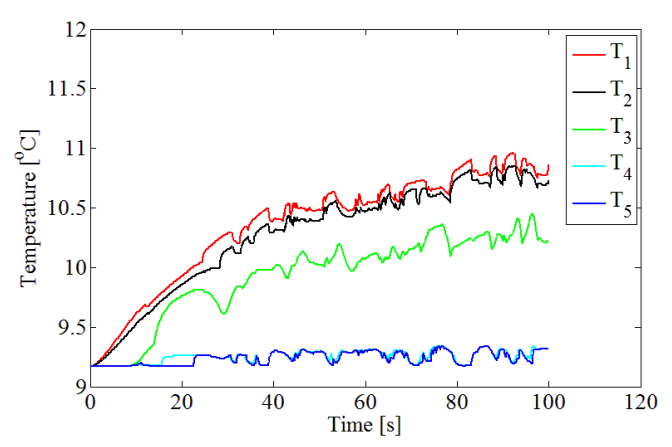

(a) Localization in heating section

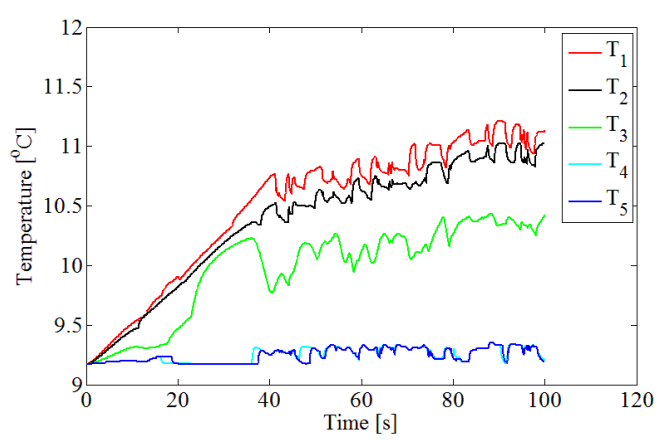

(b) Localization in middle section

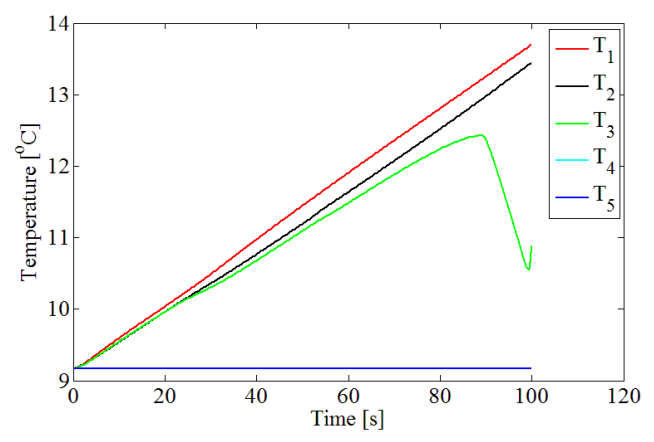

(c) Localization in cooling section

Figure 17. Temperature histories of pipe wall in different initial distributions $\left(Q_{i n}=\mathbf{2 . 6}[\mathrm{W}]\right)$

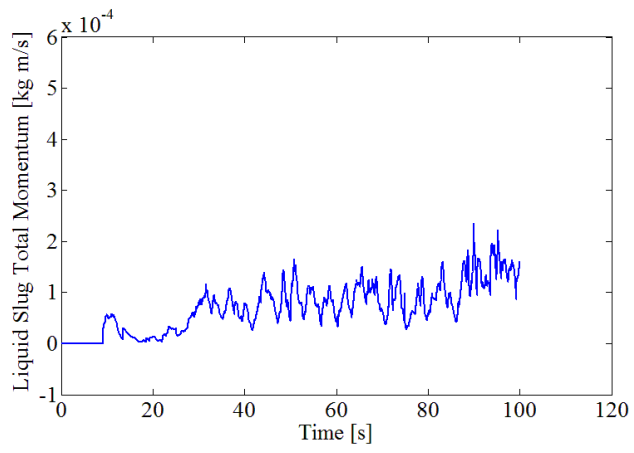

(a) Localization in heating section

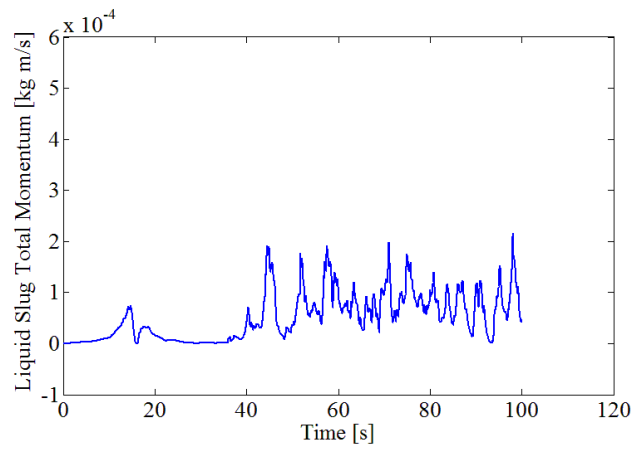

(b) Localization in middle section

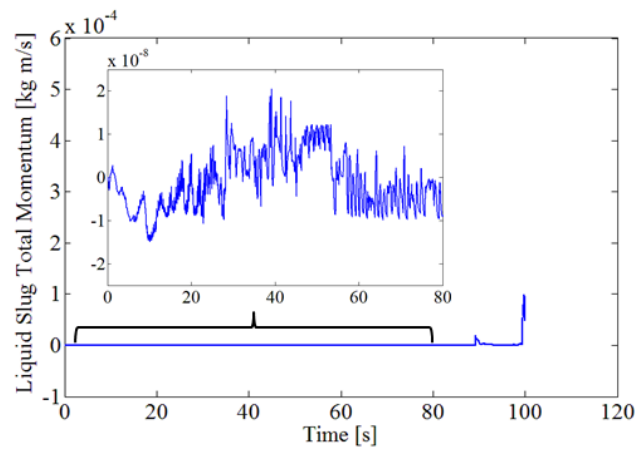

(c) Localization in cooling section

Figure 18. Total momentum of liquid slugs in different initial distributions $\left(Q_{i n}=2.6[\mathrm{~W}]\right)$

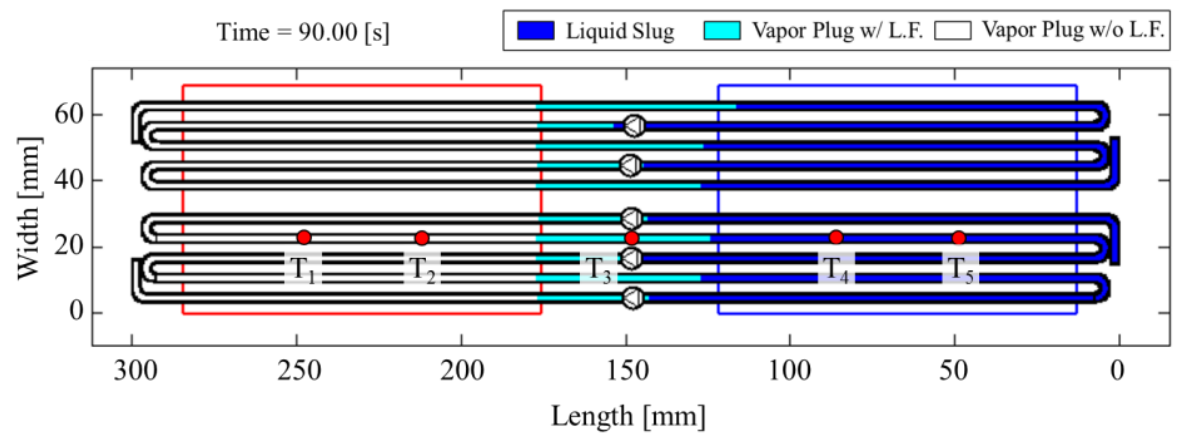

Figure 19. Position of working fluid

(Localization in cooling section, $Q_{i n}=2.6[\mathrm{~W}]$ at $90[\mathrm{~s}]$ )

11

International Conference on Environmental Systems 


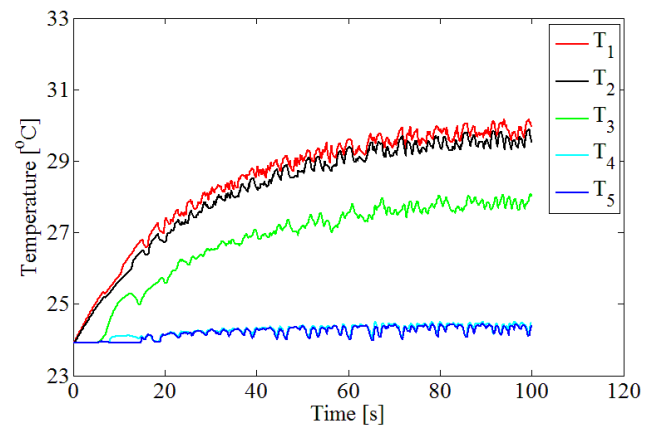

(a) Localization in heating section

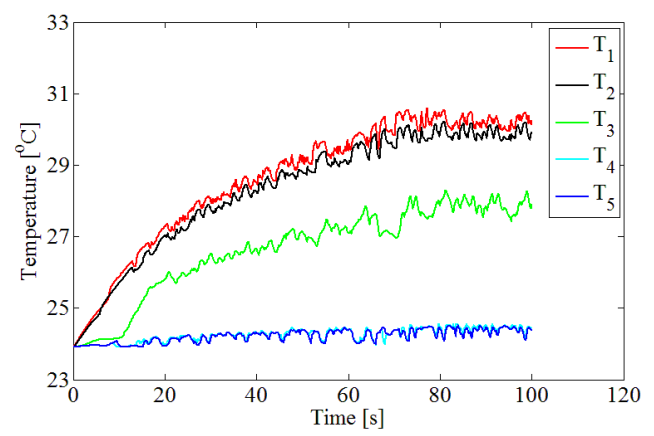

(b) Localization in middle section

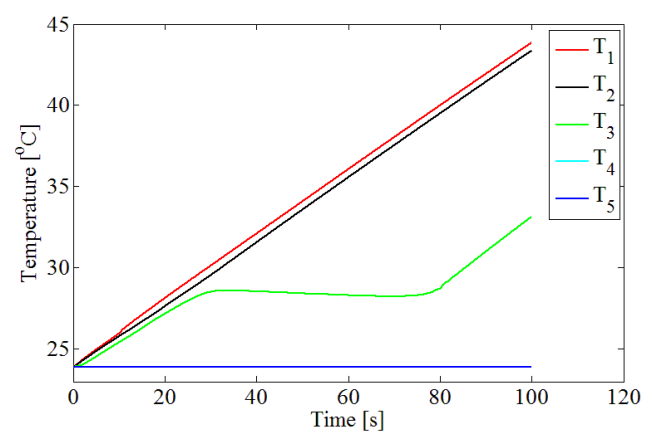

(c) Localization in cooling section

Figure 20. Temperature histories of pipe wall in different initial distributions $\left(Q_{\text {in }}=11.1[\mathrm{~W}]\right)$

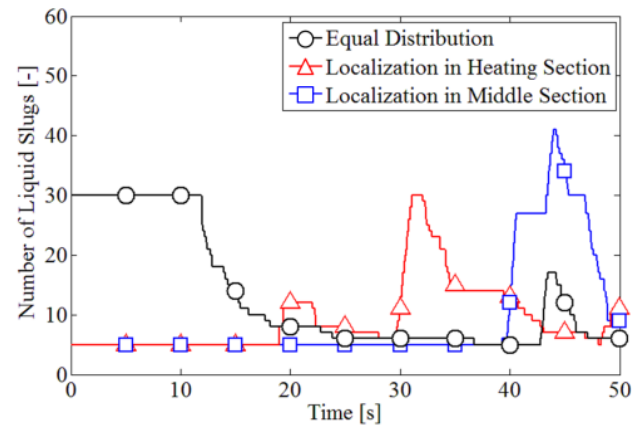

Figure 22. Number of liquid slugs $\left(Q_{i n}=2.6[\mathrm{~W}]\right)$

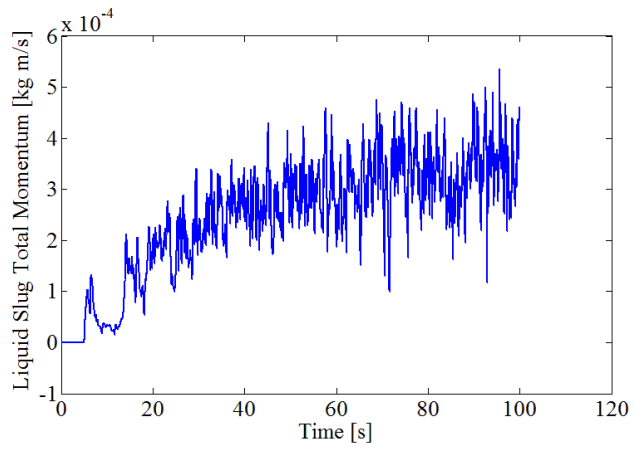

(a) Localization in heating section

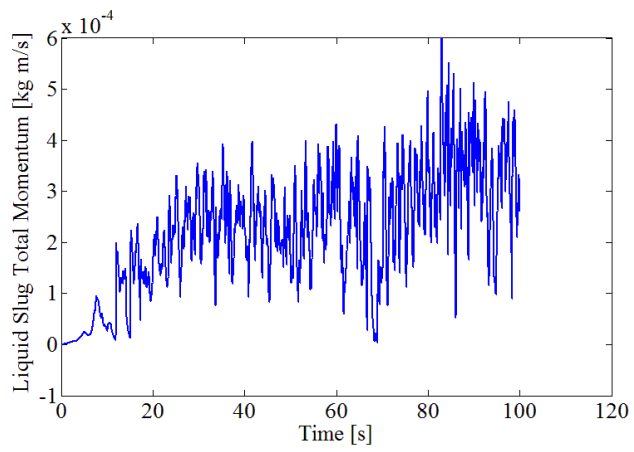

(b) Localization in middle section

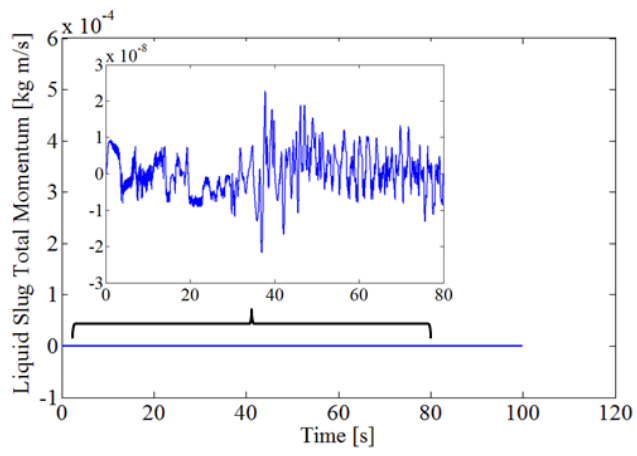

(c) Localization in cooling section

Figure 21. Total momentum of liquid slugs in different initial distributions $\left(Q_{i n}=11.1[\mathrm{~W}]\right)$

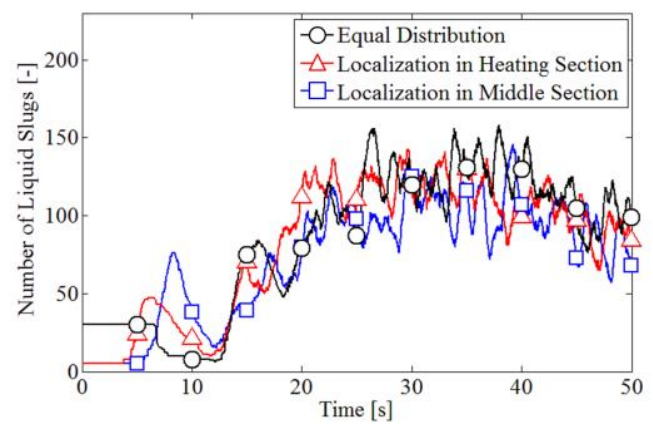

Figure 23. Number of liquid slugs $\left(Q_{i n}=11.1[\mathrm{~W}]\right)$ 
In the case of localization in the middle section, as with localization in the heating section, liquids exist in the heating section. However, the saturation temperature was higher than in the previous case because vapors also exist in the heating section. Thus, boiling did not occur until $40 \mathrm{~s}$ in this case. In the case of equal distribution, shortlength liquids existing in the heating section moved to the cooling section and merged there. Then, they made a distribution similar to localization in the middle section. Thus, boiling occurred in almost the same time as for the localization in the middle section.

These trends change at higher heat input, as shown in Figure 23. Here, boiling also occurs first in the case of localization in the heating section. However, boiling also occurs earlier in the case of localization in the middle section at around $10 \mathrm{~s}$. This change is caused by a rapid temperature rise in the pipe wall owing to higher heat input. On the other hand, boiling did not occur in the case of equal distribution at the same time as other cases because the flow was driven sufficiently by the larger pressure difference and the FHP could start without boiling. However, the histories of the liquids eventually become similar (from 20 to $50 \mathrm{~s}$ ), because the flow was fully developed by high heat input. From this result, it is clear that the effects of initial distribution become more negligible at high heat input, once the FHP can start operation.

From the above discussion, we can conclude that localization of the liquid phase in the cooling section results in difficulty starting the FHP, as expected from the results of the on-orbit experiment. No startup can occur in the initial distribution during eclipse. In addition, boiling easily triggers startup if liquid slugs exist in the heating section. Moreover, the effect of initial distribution on thermal performance is small when the FHP does startup successfully. In this study, we gained an understanding of the startup problem. However, further study is necessary to improve startup behavior with under difficult initial distribution conditions.

\section{Conclusion}

This paper presented methodology for numerical modeling of Oscillating Heat Pipes with Check Valves (CVOHP). New modeling features introduced include pipe wall energy equations, a check valves model including pressure loss, a detailed boiling algorithm, and pressure loss by transformation of the meniscus. By integrating these features, a practical numerical model for predicting the thermal performance and reproducing the phenomena inside OHPs was developed. This model was validated using on-orbit Flat-plate Heat Pipes (FHP) experimental data from JAXA. The numerical model showed good qualitative agreement with the experimental results, with an error of less than $1.7\left[{ }^{\circ} \mathrm{C}\right]$ in the temperature of the heating section. Finally, the numerical model was used to understand the startup problem in the on-orbit experiment. The model simulated several initial vapor-liquid distribution cases, which result from the thermal environment in space. Consequently, it was found that localization of liquid slugs in the cooling section results in FHP startup difficulty. Conversely, the FHP can start when liquid slugs exist in the heating section. In addition, the initial vapor-liquid distribution does not strongly affect thermal performance at steady state. These results are congruent with expected phenomena from the on-orbit experiment. A further direction of this research will be improvement of startup robustness for space application.

\section{Appendix}

\section{A. Pipe wall and plates temperature}

The energy equation for the wall is a one-dimensional heat equation dealing with heat transfer, the external heat, and working fluid. The entire tube wall is subdivided into $N_{w}$ sub-volumes, and the temperature of each sub-volume, numbered $k$, is calculated using Eq. (1):

$$
\left[c_{p, w} \rho_{w} A_{w} \frac{\partial T_{w}}{\partial t}=q_{\text {ex }} p_{\text {out }}-q_{w-f} p_{\text {in }}+k_{w} A_{w} \frac{\partial^{2} T_{w}}{\partial z^{2}}\right]_{k}
$$

where, external heat is expressed as

$$
q_{\text {ex }, k}= \begin{cases}h_{\text {contact }}\left(T_{h, n p}-T_{w, k}\right) & : \text { heating section } \\ 0 & : \text { adiabatic section } \\ h_{\text {contact }}\left(T_{c}-T_{w, k}\right) & : \text { cooling section }\end{cases}
$$

In the calculation, the temperature of the cooling plate is constant, whereas the temperature of the heating plate is calculated by considering heat input and thermal mass. In the case where the plate is divided into several nodes, conduction between nodes is also considered, as expressed in the second term in Eq. (3): 


$$
\frac{d T_{h, n p}}{d t}=\frac{Q_{\text {in }}+2 k_{\text {plate }} W_{\text {plate }} \delta_{\text {plate }}\left\{\left(T_{h, n p+1}-T_{h, n p}\right) /\left(L_{h, n p+1}+L_{h, n p}\right)+\left(T_{h, n p-1}-T_{h, n p}\right) /\left(L_{h, n p-1}+L_{h, n p}\right)\right\}}{V_{\text {plate }} \rho_{\text {plate }} c_{p, \text { plate }}}
$$

The heat flux between the pipe wall and the working fluid in each position is determined based on the position of the liquid slug, liquid film, and dry vapor. Because meshes are divided into a finite number of sections, positions are rounded off to integers in order to correspond with the sub-volume of the pipe wall. The methods used to calculate heat flux are discussed in the sections below on liquid slug and vapor plug.

\section{B. Liquid slug temperature and pressure}

The energy equations for liquid slugs are also one-dimensional heat equations, which include heat transfer with the pipe wall. The equations for both ends of a mesh are solved by using the saturation temperature of adjacent vapor plugs as boundary conditions. The number of sub-volumes in a mesh is determined according to the length of the liquid slugs at the first-time step and is maintained during calculation. The temperature change of each subvolume numbered $i$ is calculated using Eq. (4):

$$
\begin{aligned}
{\left[c_{p, l} \rho_{l} A_{c r} \frac{\partial T_{l}}{\partial t}\right.} & \left.=q_{w-f} p+k_{l} A_{c r} \frac{\partial^{2} T_{l}}{\partial z^{2}}\right]_{n, i} \\
q_{w-f, k} & =h_{l, n}\left(T_{w, k}-T_{l, n, i}\right)
\end{aligned}
$$

The value of the heat flux between the pipe wall and the liquid slug, which is expressed in Eq. (5), is calculated based on the forced convection heat transfer in the circular pipe. The heat transfer coefficient calculated in different equations depends on the flow regime of the laminar, transient, and turbulent. The inner flow regime is determined by the Reynolds number. The averaged thermal properties along with the length of the liquid slug are used to calculate these dimensionless numbers and heat transfer coefficient.

$$
\begin{gathered}
{\left[\operatorname{Re}_{l}=\frac{\rho_{l} u_{l} D_{i n}}{\mu_{l}}\right]_{n}} \\
{\left[\operatorname{Pr}_{l}=\frac{\mu_{l} c_{p, l}}{k_{l}}\right]_{n}}
\end{gathered}
$$

(a) Thermally Developing Laminar flow ${ }^{21}\left(\operatorname{Re}_{l, n}<2000\right)$

$$
\begin{gathered}
{\left[h_{l}=\left(\frac{k_{l}}{D_{\text {in }}}\right) \cdot 1.953 \cdot\left(\operatorname{Re}_{l} \operatorname{Pr}_{l} \frac{D_{\text {in }}}{L_{l}}\right)^{1 / 3}\right]_{n} \text { when }\left[\operatorname{Re}_{l} \operatorname{Pr}_{l} \frac{D_{\text {in }}}{L_{l}}\right]_{n} \geq 33.3} \\
{\left[h_{l}=\left(\frac{k_{l}}{D_{\text {in }}}\right) \cdot\left(4.364+0.0722 \operatorname{Re}_{l} \operatorname{Pr}_{l} \frac{D_{\text {in }}}{L_{l}}\right)\right]_{n} \text { when }\left[\operatorname{Re}_{l} \operatorname{Pr}_{l} \frac{D_{\text {in }}}{L_{l}}\right]_{n}<33.3}
\end{gathered}
$$

(b) Transient flow ${ }^{22}\left(2000 \leqq \operatorname{Re}_{l, n} \leqq 10000\right)$ Gnielinski correlation

$$
\left[h_{l}=\left(\frac{k_{l}}{D_{i n}}\right) \cdot\left(\frac{\left(f_{\tau} / 8\right)\left(\operatorname{Re}_{l}-10^{3}\right) \operatorname{Pr}_{l}}{1+12.7\left(f_{\tau} / 8\right)^{1 / 2}\left(\operatorname{Pr}_{l}^{2 / 3}-1\right)}\right)\right]_{n}
$$

where, $f_{\tau}$ is the friction factor of the liquid slug.

(c) Turbulent flow ${ }^{22}\left(\operatorname{Re}_{l, n}>10000\right)$ Dittus-Boelter correlation

$$
\left[h_{l}=\left(\frac{k_{l}}{D_{\text {in }}}\right) \cdot 0.023 \operatorname{Re}_{l}^{0.8} \operatorname{Pr}_{l}^{0.4}\right]_{n}
$$

Assuming the pressure of liquid slugs to be linear along its length, the pressure of adjacent vapor plugs is used as boundary conditions. In addition, a pressure drop exists at the interface between liquid and vapor, because the 
interface becomes rounded in a capillary tube. Considering that the radius of menisci is equal to the inner radius of the pipe, Laplace's equation is applied for pressure difference:

$$
P_{l, n, 1}=P_{v, j}-\frac{2 \sigma}{r_{i n}}, P_{l, n, L_{l, n}}=P_{v, j+1}-\frac{2 \sigma}{r_{i n}}, P_{l, n, i}=P_{l, n, 1}+\frac{i-z_{b, n}}{L_{l, n}}\left(P_{l, n, L_{l, n}}-P_{l, n, 1}\right)
$$

\section{Vapor plugs temperature, mass, volume, and pressure}

In this model, the temperature within each vapor plug is uniform because the density is much smaller than in the liquid phase and the heat transfer rate is much faster in the vapor phase. Therefore, the total energy balance is considered in each bulk of vapor. Figure A.1 shows the heat transfer path for the vapor plug. Eq. (13) considers the heat transfer between the tube wall and the vapor. In the region where a liquid film exists, the saturation temperature at vapor pressure is used to calculate the heat flux, because the vapor-liquid film interface should be the saturation condition. Simultaneously, this means that a steep temperature gradient exists around the vapor and

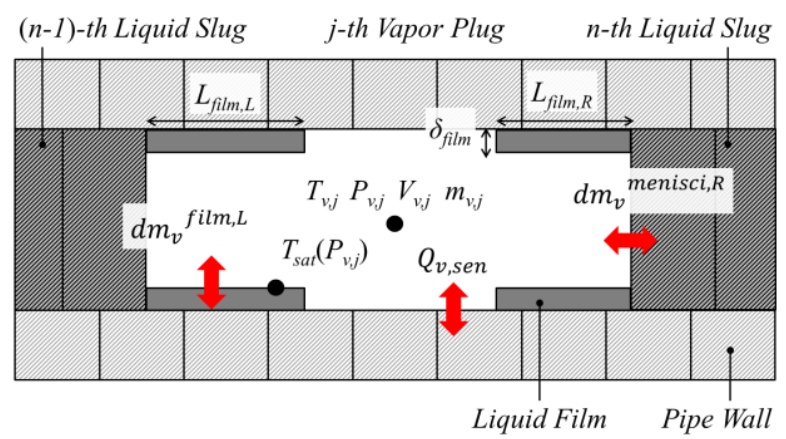

Figure A.1. Schematic of the vapor plug sub-section

liquid film. Moreover, different liquid film thicknesses are used in the evaporation and condensation regions, because the film thickness can change during phase changes. On the other hand, in regions where liquid film does not exist, heat transfer can be forced convection heat transfer between the pipe wall and dry vapor. The same equations used for liquid slugs are used to calculate the heat transfer coefficient in dry regions. The total amount of sensible heat is estimated by integrating the length of the dry region, as in Eq. (14):

$$
\begin{gathered}
q_{w-f, k}=\left\{\begin{array}{c}
k_{l, k} / \delta_{f i l m}\left(T_{w, k}-T_{\text {sat }, j}\right) \\
h_{v, j}\left(T_{w, k}-T_{v, j}\right)
\end{array}\right. \\
\left.Q_{v, \text { sen }}=\int d r y\left(q_{w-f} p_{\text {in }}\right) d z\right\rfloor_{j}
\end{gathered}
$$

In the liquid film region and the interface with liquids, heat is transferred via the phase change phenomenon of evaporation or condensation. Thus, mass transfer occurs between vapor plugs and liquid films (or liquid slugs). The amount of mass change is expressed by Eq. (15). In the equation, the first and second terms represent the phase change in the liquid film region on both sides of the vapor plug, as written in Eq. (16). For the phase change in the interface, heat conduction is considered with boundary condition of the liquid temperature as written in Eq. (17). As results of mass change, energy can come into the vapor plug as expressed in Eq. (18). Note that the heat transferred by phase change is not direct integration of heat flux here.

$$
\begin{aligned}
& {\left[\frac{d m_{v}}{d t}=d m_{v}^{f i l m, R}+d m_{v}^{f i m, L}+d m_{v}^{\text {menisci,R }}+d m_{v}^{\text {menisci, } L}\right] j} \\
& d m_{v}^{f i l m, R}=\left\{\left[\iint_{f i l m, R}\left(q_{w-f} p_{i n}\right) d z\right\} / H_{L G}\right\rfloor_{j}, d m_{v}^{\text {film,L}}=\left\lfloor\left\{\int^{L_{f i l m, L}}\left(q_{w-f} p_{\text {in }}\right) d z\right\} / H_{L G}\right\rfloor_{j} \\
& d m_{v}^{\text {menisci, }, R}=\left[\left\{\frac{k_{l}}{d z}\left(T_{l, n, 1}-T_{s a t}\right)\right\} / H_{L G}\right]_{j}, d m_{v}^{\text {menisci, } L}=\left[\left\{\frac{k_{l}}{d z}\left(T_{l, n-1, L l, n}-T_{s a t}\right)\right\} / H_{L G}\right]_{j} \\
& \left\lfloor Q_{v, l a t}=d m_{v} R T_{v}\right\rfloor_{j}
\end{aligned}
$$

Finally, the temperature change of the vapor plug is calculated using Eq. (19), where the energy changes by means of sensible heat in the dry region, phase change in the liquid film region, and work on vapor for adjacent liquid slugs, are integrated. 


$$
\left[\frac{d T_{v}}{d t}=\frac{Q_{v, \text { sen }}+Q_{v, l a t}-P_{v} d V_{v}}{c_{v, v} m_{v}}\right]_{j}
$$

The volume change of vapor can be calculated from the velocities of the adjacent liquid slugs:

$$
\left\lfloor d V_{v}=A_{c r}\left(u_{l, n}-u_{l, n-1}\right)\right\rfloor_{j}
$$

Using, mass, temperature, and vapor, the pressure of the vapor are calculated via the ideal gas law expressed in Eq. (21). It is important to note that the pressure cannot exceed the saturation pressure in the vapor temperature. If the pressure is higher than the saturation pressure, then the ideal gas law is no longer valid, and the pressure is set to the saturation pressure, calculated using Eq. (22):

$$
\begin{gathered}
{\left[P_{v}=m_{v} R T_{v} / V_{v}\right]_{j}} \\
{\left[P_{v}=P_{\text {sat }}\left(T_{v}\right)\right]_{j} \text { when }\left[P_{v}>P_{\text {sat }}\left(T_{v}\right)\right]_{j}}
\end{gathered}
$$

\section{Liquid film length and thickness}

The liquid film is assumed to have a constant thickness in the evaporation and condensation regions. In our opinion, the film becomes thicker, and does not extend in length as condensation occurs. Thus, length change due to phase change is considered only in the evaporative region. However, length change due to movement of liquid slugs should be taken into account in both regions. ${ }^{11,12}$ The change in liquid film length on the right and left sides is expressed as,

$$
\begin{aligned}
& \frac{d L_{\text {film }, R}}{d t}= \begin{cases}0 & \text { if } L_{\text {film }, R}=0, u_{l, n}<0 \\
-d m_{v}^{\text {film }, R, \text { evap }} /\left(\rho_{l} \pi D_{\text {in }} \delta_{\text {film,evap }}\right)+u_{l, n} & \text { if } L_{\text {film }, R} \neq 0\end{cases} \\
& \frac{d L_{\text {film }, L}}{d t}= \begin{cases}0 & \text { if } L_{\text {film }, L}=0, u_{l, n-1}>0 \\
-d m_{v}^{\text {film }, L, \text { evap }} /\left(\rho_{l} \pi D_{\text {in }} \delta_{\text {film,evap }}\right)-u_{l, n-1} & \text { if } L_{\text {film }, L} \neq 0\end{cases}
\end{aligned}
$$

When the distance between the liquid films on each side is zero, a breaking point in the film will be set by considering the dewetting phenomenon. The breaking point is decided based on the location where the pipe temperature is highest in the liquid film region.

The liquid film thickness is a completely fitting parameter. However, one may use the data fit obtained for the isothermal case. ${ }^{23,24}$ According to it, the film thickness is expressed as Eq. (25). To determine the liquid film thickness, the mean velocity of liquid slugs should be assumed in advance of the calculation:

$$
\delta_{\text {film }}=D_{\text {in }} \frac{0.67 C a_{l}^{2 / 3}}{1+3.35 C a_{l}^{2 / 3}}
$$

where, the capillary number is the ratio of viscosity and surface tension:

$$
C a_{l}=\frac{\mu_{l} u_{l}}{\sigma_{l}}
$$

\section{E. Liquid slugs, momentum and velocity}

The momentum equation for liquid slugs is written by following the pressure difference equation. The liquid slug is treated with a bulk parameter approach. Thus, the thermal properties of the liquid slug are averaged values in this section. The left hand side of Eq. (27) defines the change in momentum at each time step:

$$
\left[\frac{d \dot{m}_{l}}{d t}=A_{c r}\left(d P_{v}-d P_{\tau}-d P_{t u r n}-d P_{C V}\right)\right]_{n}
$$


The first term on the right hand side is the pressure difference between adjacent vapor plugs. This term is the driving force of the liquid slug. The pressure difference is calculated using the values for the two adjacent vapor plugs.

$$
d P_{v, n}=\left\{P_{v}\left(T_{v}\right)\right\}_{j}-\left\{P_{v}\left(T_{v}\right)\right\}_{j+1}
$$

The pressure loss in the circular pipes is given by Eq. (29) and the friction factor is calculated for the cases of laminar and turbulent flow regimes. Flow regime is determined from the Reynolds number of each liquid slug.

$$
\left[d P_{\tau}=\frac{f_{\tau}}{2 D_{\text {in }}}\left(1-\eta_{\text {turn }}\right) L_{l} \rho_{l} u_{l}^{2}\right]_{n}
$$

In the laminar flow regime, the effects of transformation of the meniscus on pressure loss are taken into account.

(a) Laminar flow with transformation of menisci ${ }^{25}\left(\operatorname{Re}_{l, n}<2000\right)$

$$
\left[f_{\tau}=\frac{64}{\mathrm{Re}_{l}}\left\{1+0.17 \frac{D_{\text {in }}}{L_{l}}\left(\frac{\mathrm{Re}_{l}}{C a_{l}}\right)^{0.33}\right\}\right]_{n}
$$

(b) Turbulent flow ${ }^{26}\left(\operatorname{Re}_{l, n} \geqq 2000\right)$

$$
\left\lfloor f_{\tau}=0.3164 \mathrm{Re}_{l}^{-0.25}\right\rfloor_{n}
$$

The third term on the right hand side is the pressure loss in the turn sections, which is defined in Eq. (32). The friction factor, $f_{K}$, is calculated as the ratio of the friction factor in the straight sections. ${ }^{27,28}$ The transient Reynolds number is determined using Eq. (36).

$$
\left[d P_{\text {turn }}=\frac{f_{K}}{2 D_{\text {in }}} \eta_{\text {turn }} L_{l} \rho_{l} u_{l}^{2}\right]_{n}
$$

(a) Laminar flow ${ }^{27}\left(\operatorname{Re}_{l}<\operatorname{Re}_{\text {turn }}\right)$

$$
\left\lfloor f_{\text {turn }}=f_{\tau}\left\{0.1008 D e^{1 / 2}\left(1+3.945 D e^{-1 / 2}+7.782 D e^{-1}+9.097 D e^{-3 / 2}+5.608 D e^{-2}\right)\right\}\right\rfloor_{n}
$$

(b) Turbulent flow ${ }^{28}\left(\operatorname{Re}_{l} \geqq \operatorname{Re}_{\text {turn }}\right)$

$$
\left[f_{\text {turn }}=f_{\tau}\left\{\operatorname{Re}_{l}\left(\frac{D_{\text {in }}}{2 r_{\text {turn }}}\right)^{2}\right\}^{0.05}\right]_{n}
$$

where, Dean number, De, is calculated using Eq. (35):

$$
\begin{gathered}
{\left[D e=\operatorname{Re}_{l} \sqrt{\frac{D_{\text {in }}}{2 r_{\text {turn }}}}\right]_{n}} \\
{\left[\operatorname{Re}_{\text {turn }}=2 \times 10^{4}\left(\frac{D_{\text {in }}}{2 r_{\text {turn }}}\right)^{0.32}\right]_{n}}
\end{gathered}
$$

$\eta_{\text {turn }}$ is the spatial ratio of a portion of liquid slug located in the turn section. If the liquid slug exists completely in the straight tube section, then the spatial ratio is zero:

$$
\left[\eta_{\text {turn }}=\frac{L_{l, t u r n}}{L_{l}}\right]_{n}
$$


When the liquid slug flows through the check valve, pressure loss by several factors has to be taken into account. As shown in Figure A.2, the pressure loss in the check valve can be considered by breaking it down into contraction flow, expansion flow, and drag of the ball. (Pressure loss via the ball stopper is ignored here.) The total pressure loss and each factor can be described as follows:

$$
\left[d P_{C V}=\frac{\xi_{1}+\zeta_{2}+\zeta_{3}}{2} \rho_{l} u_{l}^{2}\right]_{n}
$$

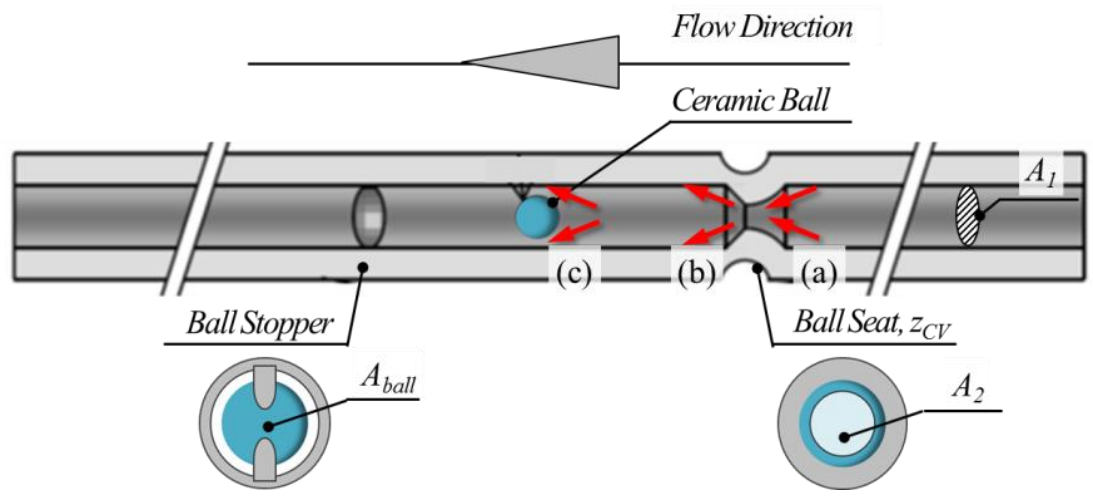

Figure A.2. Schematic of the check valve

(a) Contraction flow in the ball seat ${ }^{26}$

$$
\zeta_{1}=0.04+\left(1+\frac{A_{2}}{A_{C}}\right)^{2} \text { where } \frac{A_{C}}{A_{2}}=0.582+\frac{0.0418}{1.1-\sqrt{A_{2} / A_{1}}}
$$

(b) Expansion flow in the ball seat ${ }^{26}$

$$
\zeta_{2}=\left(1+\frac{A_{1}}{A_{2}}\right)^{2}
$$

(c) Drag of the ball ${ }^{26}$

$$
\zeta_{3}=\frac{C_{D} A_{\text {ball }}}{A_{1}} \text { where } C_{D}=0.47 \text { (in the case of a spherical body) }
$$

The function of the check valve is reproduced by changing the mass flow rate of the liquid slug. If the position of the liquid slug overlaps the position of the ball seat in the check valve, $z_{C V}$, the mass flow rate is allowed only in the direction of the check valve. In this model, the time delay associated with moving the ball is neglected in order to simplify the model.

$$
\dot{m}_{l, n}=0 \text { when } z_{b, n} \leq z_{c v}, z_{f, n}>z_{c v} \text { and } \dot{m}_{l, n}<0
$$

Finally, the velocity of the liquid slug is estimated from the momentum of the liquid slug at each time step.

$$
\left[u_{l}=\frac{\dot{m}_{l}}{A_{c r} L_{l} \rho_{l}}\right]_{n}
$$




\section{F. Merging algorithm}

As a result of volume and mass changes in the vapor plugs, the vapor plugs may collapse and the liquid slugs merge into each other. In such a case, the meshes of the liquid slugs are combined for temperature calculation. Further, the momentum and length of the new liquid slug are set to the sum of the values of the old merged liquid slugs:

$$
\begin{gathered}
\dot{m}_{l, n, \text { new }}=\dot{m}_{l, n, \text { old }}+\dot{m}_{l, n-1, \text { old }}, L_{l, n, \text { new }}=L_{l, n, \text { old }}+L_{l, n-1, \text { old }} \\
\text { when } V_{v, j}<0 \text { or } m_{v, j}<0
\end{gathered}
$$

\section{G. Boiling algorithm}

A boiling phenomenon in the liquid phase is reproduced by creating a new vapor plug. For the boiling criterion, the superheat degree is used. The superheat degree is defined by Eq. (45):

$$
\begin{gathered}
\Delta T_{\text {sat }, k}=T_{w, k}-T_{s a t}\left(P_{l, n, i}\right) \\
\Delta T_{\text {sat, boiling }}=\frac{r_{\max }}{k_{l}} q_{e x}+\frac{2 \sigma T_{s a t}\left(P_{l, n, i}\right)}{H_{L G} \rho_{v} r_{\max }} \\
V_{v, \text { new }}=A_{c r} D_{\text {in }}, P_{v, \text { new }}=P_{l, n, i}+\frac{2 \sigma}{r_{\text {in }}} \\
T_{v, \text { new }}=T_{\text {sat }}\left(P_{v, \text { new }}\right), m_{v, \text { new }}=\rho_{\text {sat }}\left(T_{v, \text { new }}\right) V_{v, \text { new }}
\end{gathered}
$$

If the superheat degree is higher than the required value, calculated using Eq. (46), a new vapor plug is created at that position. The initial values of the new vapor plug are set using Eq. (47).

Eq. (46) considers the Clausius-Clapeyron equation and the Laplace equation in the active cavity for boiling. Regarding the radius of a maximum active cavity, see the relevant study conducted by Hino and Ueda ${ }^{29,30}$. They conducted a flow boiling experiment using stainless steel and CFC-113 and estimated the size of the cavity using the fitting of Eq. (46). They finally decided that the radius of the maximum cavity was in the range $0.22-0.34[\mu \mathrm{m}]$ in their experiment. However, prehistory in the flow channel strongly affects this value. In an OHP, liquid slugs and vapor plugs flow alternately and the pipe wall dries very easily compared to the liquid single-phase flow. Thus, the size of the cavity can be larger than the size used in the experiment conducted by Hino and Ueda. More research is necessary to find the exact value, but we assumed $1[\mu \mathrm{m}]$ as the radius of the cavity in this study.

Simultaneously, with the creation of the new vapor plug, the original liquid slug divides into two liquid slugs, as shown in Figure A.3. At that time, temperature meshes, length, and the momentum of liquid slugs separate from the position where the boiling is occurring.

$$
\begin{gathered}
L_{l, n, \text { new }}=k-z_{b, n \text {,old }}, L_{l, n+1, \text { new }}=z_{f, n, \text { old }}-k \\
\dot{m}_{l, n, \text { new }}=\dot{m}_{l, n, \text { old }} \frac{L_{l, n, \text { new }}}{L_{l, n, \text { old }}}, \dot{m}_{l, n+1, \text { new }}=\dot{m}_{l, n, \text { old }} \frac{L_{l, n+1, \text { new }}}{L_{l, n, \text { old }}}
\end{gathered}
$$

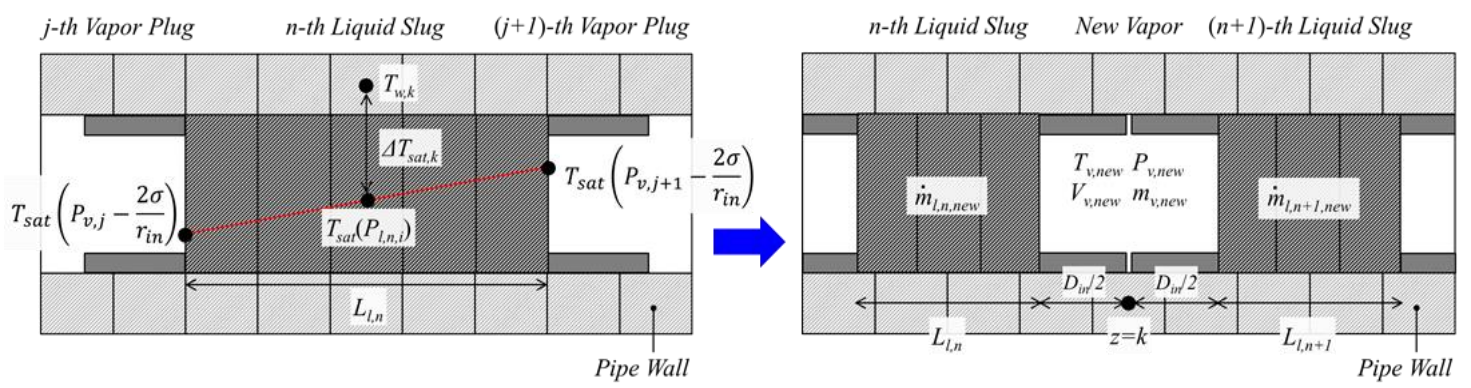

Figure A.3. Schematic of the boiling algorithm 


\section{Acknowledgments}

This work was partially supported by a Japan Society for the Promotion of Science (JSPS) Grant-in-Aid for JSPS Fellows (Grant No. 26-3928).

\section{References}

${ }^{1}$ Akachi, H., U.S. Patent, Patent Number 4921041, May 1, 1990.

${ }^{2}$ Akachi, H., Polasek, F., and Stulc, P., "Pulsating Heat Pipes," Proceedings of the 5th International Heat Pipe Symposium, Melbourne, Australia, 1996, pp. 208-217.

${ }^{3}$ Khandekar S., and Groll, M., "An Insight into Thermos-Hydrodynamic Coupling in Closed Loop Pulsating Heat Pipes," International Journal of Thermal Sciences, Vol.43, 2004, pp.13-20.

${ }^{4}$ Charoensawan, P., Khandekar, S., Groll, M., and Terdtoon, P., "Closed Loop Pulsating Heat Pipes Part A: Parametric Experimental Investigations," Applied Thermal Engineering, Vol. 23, 2003, pp. 2009-2020.

${ }^{5}$ Khandekar, S., Charoensawan, P., Groll, M., and Terdtoon, P., "Closed Loop Pulsating Heat Pipes Part B: Visualization and Semi-Empirical Modeling," Applied Thermal Engineering, Vol. 23, 2003, pp. 2021-2033.

${ }^{6}$ Miyazaki, Y., and Akachi, H., "Self Excited Oscillation of Slug Flow in a Micro Channel," Proceedings of the Third International Conference on Multiphase Flow, Lyon, France, 1998.

${ }^{7}$ Miyazaki, Y., and Arikawa, M., "Oscillatory Flow in the Oscillating Heat Pipe," Proceedings of the 11th International Heat Pipe Conference, Tokyo, Japan, 1999, pp. 367-372.

${ }^{8}$ Gully, P., Bonnet, F., Nikolayev, V., Luchier, N., and Tran, T., "Evaluation of the Vapor Thermodynamic State in PHP," Proceedings of the 17th International Heat Pipe Conference, Kanpur, India, 2013.

${ }^{9}$ Nikolayev, V., "Oscillatory Instability of the Gas-Liquid Meniscus in a Capillary under the Imposed Temperature Difference," International Journal of Heat and Mass Transfer, Vol. 64, 2013, pp. 313-321.

${ }^{10}$ Miyazaki, Y., Kawai, H., Iwata, N., and Ogawa, H., "Operational Limit of Oscillating Heat Pipes," Proceedings of the 16th International Heat Pipe Conference, Lyon, France, 2012.

${ }^{11}$ Miyazaki, Y., Polasek, F., and Akachi, H., "Oscillating Heat Pipe with Check Valves," Proceedings of the 6th International Heat Pipe Symposium, Chiang Mai, Thailand, 2000, pp. 389-393.

${ }^{12}$ Maeda, M., Okamoto, A., Kawasaki, H., and Sugita, H., "Development of Flat Plate Heat Pipe and the Project of On-orbit Experiment," Proceedings of the 41 st Int. Conf. on Environmental Systems, Portland, U.S., 2011, AIAA 2011-5142.

${ }^{13}$ Okamoto, A., Ando, M., and Sugita, H., "Initial Evaluation of On-orbit Experiment of Flat-Plate Heat Pipe," Proceedings of the 17th International Heat Pipe Conference, Kanpur, India, 2013.

${ }^{14}$ Ohtani, T., Nakamura, Y., Takahashi, Y., Inoue, K., and Hirako, K., “JAXA SDS-4 Spacecraft System Design and Test Results," Proc of the 8th IAA Symposium on Small Satellites for Earth Observation, IAA-B8-1004, Berlin, Germany, 2011.

${ }^{15}$ Ando, M., Okamoto, A., Maeda, M., and Sugita, H., "Evaluation of On-orbit Experiment of Flat-plate Heat Pipe," Presentation file of the 2013 Spacecraft Thermal Control Workshop, Los Angeles, California, 2013.

${ }^{16}$ Okamoto, A., Ando, M., and Sugita, H., "On-orbit Performance Evaluation of Oscillating Heat Pipes with Check Valves," Proceedings of the International Conference on Heat Pipes for Space Application, Moscow, Russia, 2014.

${ }^{17}$ Daimaru, T., Yoshida, S., Nagai, H., Okamoto, A., Ando, M., and Sugita, H., "Mathematical Modeling and Experimental Validation of Oscillating Heat Pipes," Proc of $44^{\text {th }}$ Int. Conf. on Environmental Systems, Tucson, Arizona, 2014 , Paper No. ICES-2014-121.

${ }^{18}$ Shafii, M.B., Faghri, A., and Zhang, Y., "Thermal Modeling of Unlooped and Looped Pulsating Heat Pipes," Journal of Heat Transfer, Vol. 123, 2001, pp. 1159-1172.

${ }^{19}$ Das, S.P., Nikolayev, V.S., Lefevre, F., Pottier, B., Khandekar, S., and Bonjour, J., "Thermally Induced Two-Phase Oscillating Flow Inside a Capillary Tube,” International Journal of Heat and Mass Transfer, Vol. 53, 2010, pp. $3905-3913$.

${ }^{20}$ Nikolayev, V., “A Dynamic Film Model of the Pulsating Heat Pipe," Journal of Heat Transfer, Vol. 133, 2011, pp. 081504$1-9$.

${ }^{21}$ Shah, R.K., "Thermal Entry Length Solutions for the Circular Tube and Parallel Plates," Proceedings of the 3rd National

Heat Mass Transfer Conference, Vol. I, Paper HMT-11-75., IIT Bombay, 1975.

${ }^{22}$ Incropera, F.P., and DeWitt, D.P., Fundamentals of Heat and Mass Transfer, 6th edition, Wiley, 2007.

${ }^{23}$ Bretherton, F., "The Motion of Long Bubbles in Tubes," Journal of Fluid Mechanics, Vol. 10, 1961, pp. 166-188.

${ }^{24}$ Aussillous, P., and Quéré, D., "Quick Deposition of a Fluid on the Wall of a Tube," Physics of Fluid, Vol. 12, No. 10, 2000, pp. 2367-2371.

${ }^{25}$ Kreutxer, T.M., Kapteijn, F., Mouljin, A.J., Kleijn, R.C., and Heisxwolf, J.J., "Inertial and Interfacial Effects on pressure Drop of Taler Flow in Capillaries," AIChE Journal, Vol. 51, No. 9, 2005, pp. 2428-2440.

${ }^{26}$ Rieutord, M., Fluid Dynamics: An Introduction, 2015 edition, 2015.

${ }^{27}$ Ito, H., "Laminar Flow in Curved Pipes," Journal of Applied Mathematics and Mechanics, Vol. 40, 1969, pp. $653-663$.

${ }^{28}$ Ito, H., "Friction Factors for Turbulent Flow in Curved Pipes," Journal of Basic Engineering, Vol. 81, No. 2, 1959, pp. 123134.

${ }^{29}$ Hino, R., and Ueda, T., "Studies on Heat Transfer and Flow Characteristics in Subcooled Flow Boiling Part 1. Boiling Characteristics," International Journal of Multiphase Flow, Vol. 11, No. 3, 1985, pp. 269-281.

${ }^{30}$ Hino, R., and Ueda, T., "Studies on Heat Transfer and Flow Characteristics in Subcooled Flow Boiling Part 2. Flow Characteristics," International Journal of Multiphase Flow, Vol. 11, No. 3, 1985, pp. 283-297. 